\title{
Pesquisa em Gestão da Produção na indústria de calçados: revisão, classificação e análise
}

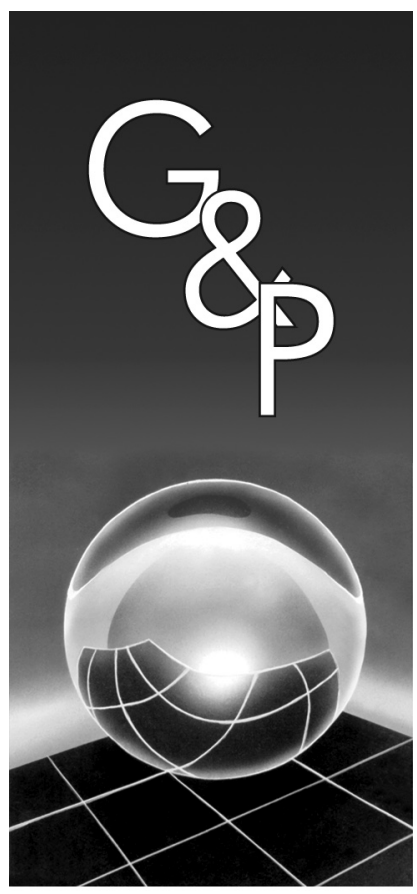

\author{
Moacir Godinho Filho \\ Flávio César Faria Fernandes \\ Andrey Domingues de Lima
}

Resumo

Este trabalho apresenta uma revisão bibliográfica que pretende ser completa (209 trabalhos) sobre Gestão da Produção na indústria calçadista a partir do ano 1980, revisão esta não encontrada até agora na literatura de Gestão da Produção. A partir de tal revisão propôs-se um sistema de classificação baseado em 5 categorias: origem do trabalho; grande área da Engenharia de Produção focada no trabalho; subárea da Engenharia de Produção focada no trabalho; procedimento de pesquisa utilizado; e fonte do trabalho, que serviu para classificar e estruturar os artigos da revisão. Uma vez classificada e estruturada, a revisão bibliográfica sobre Gestão da Produção na indústria calçadista serviu de base para uma ampla análise do tema. Essa análise se baseou em dois pontos fundamentais: i) um estudo quantitativo das grandes áreas da Engenharia de Produção focadas nos trabalhos, assim como da origem, fonte e procedimentos de pesquisa utilizados nos trabalhos; e ii) um estudo qualitativo dos principais assuntos e objetivos alcançados por esses trabalhos. As principais contribuições deste trabalho são: servir de base para um maior conhecimento da literatura atualmente sobre Gestão da Produção na indústria de calçados e propor sugestões de pesquisas futuras na área.

Palavras-chave: Indústria de calçados. Gestão da Produção. Revisão bibliográfica.

\section{Introdução}

O presente trabalho trata do tema Gestão da Produção na indústria calçadista. A indústria calçadista nacional contribui com uma parcela significativa das atividades manufatureiras do País, distinguindo-se por sua crescente importância na pauta de exportações do Brasil, pelo seu volume de produção, por sua organização em polos produtores integrados, como também pela sua grande capacidade de geração de empregos. Entretanto, no atual contexto de mercado globalizado, caracterizado por mudanças tecnológicas, comunicação rápida, abertura econômica e competição global, pode-se notar o declínio da competitividade da indústria calçadista brasileira. Sendo assim, o presente trabalho torna-se oportuno por compilar, por meio de uma classificação de trabalhos que abordam esta importante indústria, muitas informações técnico-científicas que podem ser utilizadas para elevar a indústria brasileira de calçados em patamares tecnológicos e competitivos mais altos.

A importância das classificações dentro da atividade científica é clara; o conhecimento científico se baseia na classificação. Portanto, a realização de uma classificação é uma ferramenta essencial para o conhecimento de uma determinada área.

Para Good (1965), as classificações podem servir aos seguintes propósitos: i) conhecimento mental e comunicação; ii) descoberta de novo campo de pesquisa; iii) planejamento de uma estrutura organizacional ou estrutura de uma máquina; iv) lista de conferência; e v) entretenimento.

A classificação a ser apresentada neste trabalho se insere principalmente no grupo (i) e no grupo (ii), ou seja, a classificação apresentada servirá para um maior conhecimento das pesquisas já realizadas na indústria de calçados com relação ao tema Gestão de Produção, além da proposição de pontos importantes a serem estudados em futuras pesquisas.

A estrutura metodológica do trabalho é composta por cinco passos:

- Passo 1: realização de uma pesquisa (survey) sobre trabalhos em Gestão da Produção na indústria de calçados, sendo que diversas bases de dados foram consultadas, entre elas Compendex, Emerald, Sciende Direct, Scielo e Web of Science. 
- Passo 2: Proposta de um sistema de classificação sobre este tema, segundo 5 parâmetros: origem do trabalho; grande área da Engenharia de Produção (EP) focada no trabalho; subárea da EP focada no trabalho; procedimento de pesquisa utilizado; e fonte do trabalho.

- Passo 3: classificação da literatura sobre Gestão da Produção na indústria de calçados.

- Passo 4: estruturação da revisão da literatura.

- Passo 5: análise do tema. Os outputs da pesquisa são um maior conhecimento do tema, bem como a sugestão de novas pesquisas dentro do tema.

Este trabalho é estruturado como segue: na seção 2 é abordada a participação do calçado brasileiro nas exportações e o crescimento do mercado interno; na seção 3 é mostrado o sistema de classificação proposto, bem como sua utilização para a classificação e codificação dos trabalhos encontrados na revisão bibliográfica efetuada; na seção 4 a revisão da literatura é estruturada; na seção 5 são apresentadas análises sobre o tema, bem como sugeridas pesquisas futuras; e na seção 6 são tecidas algumas conclusões.

\section{A indústria de calçados no Brasil}

A participação do setor coureiro-calçadista no total de exportações brasileiras foi de 3\% em 2005 (Revista Courobusiness, edição $n^{\circ}$ 58-mai/jun, 2008). A indústria brasileira de calçados apresenta um coeficiente de exportações bastante elevado, principalmente quando em comparação com a média da indústria, mensurado como da ordem de $25 \%$ do consumo aparente (www. brazilianfootwear.com.br). Isso mostra a importância da inserção das empresas do setor no mercado internacional. As exportações brasileiras são fortemente concentradas no mercado estadunidense. Os Estados Unidos são o destino de mais de 2/3 das vendas externas de calçados. Em seguida, vêm a Argentina e o Reino Unido, com participações aproximadas de $8 \%$ e $6 \%$. Os outros países que aparecem na pauta de exportações apresentam participações quase que irrelevantes (ABICALÇADOS, 2008). Além da concentração das exportações em termos do mercado-destino, verifica-se também concentração do produto exportado. Mais de $2 / 3$ das exportações brasileiras de calçados são de calçados de couro (ABICALÇADOS, 2008).

Em relação ao mercado interno, houve um crescimento (puxando o desempenho da indústria calçadista) já que as exportações vêm sofrendo com o impacto da valorização do real (ABICALÇADOS, 2008). Além disso, a invasão dos produtos chineses no mercado mundial tem obrigado a indústria calçadista a direcionar a produção para o mercado interno.

\section{Classificação dos trabalhos em Gestão da Produção voltados à indústria de calçados}

\subsection{O sistema de classificação proposto (Passos 1 e 2 da pesquisa)}

A revisão da literatura sobre Gestão da Produção na indústria calçadista foi composta por 209 trabalhos. Depois de feita esta revisão, foi proposto um sistema de classificação baseado em cinco dimensões: i) origem do trabalho; ii) grande área da Engenharia de Produção focada no trabalho; iii) subárea da Engenharia de Produção focada no trabalho; iv) procedimento de pesquisa utilizado no trabalho; e v) fonte do trabalho.

Quanto à categoria origem do trabalho, tem-se que os trabalhos encontrados podem ter duas origens: trabalho nacional $(\mathrm{N})$ ou trabalho internacional (I). Esta classificação é necessária para se estabelecer posteriormente uma relação entre a pesquisa nacional e a internacional referente à Gestão da Produção na indústria de calçados.

Para definir o assunto relativo à Gestão da Produção focado em cada um dos trabalhos pesquisados, foi necessário levantar as áreas da Gestão da Produção. Para isso identificamos grandes áreas e subáreas da Engenharia de Produção conforme uma classificação e codificação proposta pela Associação Brasileira de Engenharia de Produção (Abepro). Esta classificação é mostrada no Quadro 1.

Observa-se que a subárea Organização do Trabalho encontra-se alocada em duas grandes áreas da Engenharia de Produção (Gerência de Produção; Ergonomia e Segurança do Trabalho). Entende-se que a Organização do Trabalho relacionada à área Gerência de Produção compreende as várias abordagens de gestão: a clássica (Taylorista), a dos grupos semiautônomos entre outras. Já a Organização do Trabalho relacionada à área Ergonomia e Segurança do Trabalho aborda com maior profundidade assuntos relacionados ao relacionamento entre o homem e seu trabalho.

A subárea Redes de Empresas também está alocada em duas grandes áreas da Engenharia de Produção (Estratégia e Organizações; Gestão da Tecnologia). Entende-se que a subárea Redes de Empresas relacionada à área Estratégia e Organizações aborda com maior enfoque assuntos relacionados às redes de mercado de empresas e cadeia produtiva. A mesma subárea relacionada à área Gestão da Tecnologia tem um foco maior no estudo das mudanças técnicas, organizacionais e econômicas advindas das novas relações entre empresas.

A quarta dimensão do sistema de classificação proposto se refere ao procedimento de pesquisa utilizado. Neste trabalho utilizamos uma classificação proposta em autores como Filippine (1997); Fernandes (1999), Berto e Nakano (1998; 1999; 2000); assim compreende-se que os procedimentos 
Quadro 1. Grandes áreas e subáreas da engenharia de produção.

\begin{tabular}{|c|c|}
\hline Grande área da Engenharia de Produção & Subárea da Engenharia de Produção \\
\hline 1. Gerência de produção & $\begin{array}{l}\text { 1.1 Planejamento e controle da produção } \\
\text { 1.2 Sistemas de produção } \\
\text { 1.3 Simulação da produção } \\
\text { 1.4 Projeto de fábrica e layout } \\
\text { 1.5 Processos de fabricação } \\
\text { 1.6 Automação } \\
\text { 1.7 Gestão da manutenção } \\
\text { 1.8 Gerenciamento da construção civil } \\
\text { 1.9 Gestão agro-industrial } \\
\text { 1.10 Logística } \\
\text { 1.11 Organização do trabalho } \\
\text { 1.12 Engenharia de métodos }\end{array}$ \\
\hline 2. Qualidade & $\begin{array}{l}\text { 2.1 Gestão da qualidade } \\
\text { 2.2 Engenharia da qualidade } \\
\text { 2.3 Normalização e certificação para a qualidade } \\
\text { 2.4 Metrologia } \\
\text { 2.5 Confiabilidade de equipamentos, máquinas e produtos } \\
\text { 2.6 Qualidade em serviços }\end{array}$ \\
\hline 3. Gestão econômica & $\begin{array}{l}\text { 3.1 Engenharia econômica } \\
\text { 3.2 Gestão de custos } \\
\text { 3.3 Análise e gerenciamento de projetos } \\
\text { 3.4 Análise de investimentos }\end{array}$ \\
\hline 4. Ergonomia e segurança do trabalho & $\begin{array}{l}\text { 4.1 Organização do trabalho } \\
\text { 4.2 Ergonomia do produto } \\
\text { 4.3 Ergonomia do processo } \\
\text { 4.4 Psicologia do trabalho } \\
\text { 4.5 Segurança do trabalho e riscos industriais } \\
\text { 4.6 Biomecânica ocupacional }\end{array}$ \\
\hline 5. Engenharia do produto & $\begin{array}{l}\text { 5.1 Pesquisa de mercado } \\
\text { 5.2 Planejamento e projeto do produto } \\
\text { 5.3 Marketing do produto } \\
\text { 5.4 Gerenciamento de projeto }\end{array}$ \\
\hline 6. Pesquisa operacional & $\begin{array}{l}\text { 6.1 Programação matemática } \\
\text { 6.2 Decisão multicritério } \\
\text { 6.3 Processos estocásticos } \\
\text { 6.4 Simulação } \\
\text { 6.5 Teoria da decisão e teoria dos jogos } \\
\text { 6.6 Séries temporais } \\
\text { 6.7 Pesquisa operacional soft } \\
\text { 6.8 Inteligência computacional (redes neurais, lógica nebulosa e sistemas especialistas) }\end{array}$ \\
\hline 7. Estratégia e organizações & $\begin{array}{l}\text { 7.1 Avaliação de mercado } \\
\text { 7.2 Planejamento estratégico } \\
\text { 7.3 Estratégias de produção } \\
\text { 7.4 Organização industrial } \\
\text { 7.5 Marketing estratégico industrial } \\
\text { 7.6 Redes de empresas }\end{array}$ \\
\hline 8. Gestão da tecnologia & $\begin{array}{l}\text { 8.1 Inovação tecnológica } \\
\text { 8.2 Impactos e riscos tecnológicos } \\
\text { 8.3 Redes de empresas }\end{array}$ \\
\hline 9. Sistemas de informação & $\begin{array}{l}\text { 9.1 Sistemas de informações gerenciais } \\
\text { 9.2 Sistemas de apoio à decisão } \\
\text { 9.3 Planejamento de sistemas de informação } \\
\text { 9.4 Administração estratégica da informação }\end{array}$ \\
\hline 10. Gestão ambiental & $\begin{array}{l}\text { 10.1 Políticas ambientais } \\
\text { 10.2 Sistemas de gestão ambiental } \\
\text { 10.3 Gestão energética } \\
\text { 10.4 Gestão de resíduos }\end{array}$ \\
\hline 11. Ensino de engenharia de produção & $\begin{array}{l}\text { 11.1 Ensino de graduação } \\
\text { 11.2 Ensino de pós-graduação } \\
\text { 11.3 Metodologia de pesquisa } \\
\text { 11.4 Ensino a distância }\end{array}$ \\
\hline
\end{tabular}


de pesquisa mais utilizados na área de Gestão da Produção são: revisão bibliográfica $(\mathrm{R})$; experimental $(\mathrm{X})$; pesquisa de avaliação ou survey $(\mathrm{S})$; estudo de caso $(\mathrm{E})$; e pesquisaação (P). Uma sexta classe é a teórico-conceitual (T) que geralmente envolve modelos conceituais ou modelos matemáticos ou modelos de simulação.

A última dimensão do sistema de classificação proposto é a fonte do trabalho. As possíveis fontes de publicação identificadas foram: Congresso (C) sendo que o subíndice 1 refere-se ao ENEGEP, o 2 ao SIMPOI e o 3 ao SIMPEP; revista científica (R); livro (L); tese (T); dissertação (D); outros $(\mathrm{O})$.

\subsection{Classificação da revisão bibliográfica (Passo 3 da pesquisa)}

Nesta seção classificamos a revisão da literatura encontrada (ao todo foram encontrados 209 trabalhos). A Tabela 1 mostra a codificação dos trabalhos de acordo com o sistema proposto na seção anterior.

\section{A estruturação da revisão da literatura sobre Gestão da Produção na indústria de calçados utilizando o sistema proposto (Passo 4 da pesquisa)}

Nesta seção a revisão bibliográfica é estruturada utilizando-se a classificação das grandes áreas e subáreas da Engenharia de Produção. Apresenta-se um breve resumo de cada trabalho, tentando ilustrar as principais contribuições para a literatura sobre o tema.

\subsection{Artigos que focam prioritariamente uma única grande área da engenharia de produção}

\subsubsection{Artigos referentes à gerência da produção}

Com relação ao planejamento e controle da produção (PCP), os trabalhos de Nisancy e Suri (1980, 1981) tratam respectivamente de scheduling e da aplicação da tecnologia de grupo na indústria de calçados. Em ambos os trabalhos a simulação é utilizada. Ainda relacionados ao scheduling na indústria de calçados têm-se: o trabalho de Fanti et al. (1996), que propõe um procedimento heurístico para a determinação do número de tarefas de diferentes tipos e para o sequenciamento destas a fim de utilizar toda a capacidade de operação da máquina e minimizar a reposição de ferramentas e do tempo de set up; o trabalho de Silva e Fernandes (2002b), que propõe um método de scheduling em um ambiente controlado pelo sistema PBC (Period Batch Control); o estudo de Zangiacomi et al. (2004), que desenvolve um módulo de planejamento e sequenciamento da produção aplicado a um modelo de fábrica flexível baseado no conceito de manufatura ágil; e o trabalho de Barnett et al. (2004), que propõe um sistema de sequenciamento responsivo voltado para a produção customizada de calçados. Referente aos sistemas de controle da produção (SCP), o trabalho de Albuquerque et al. (1999) propõe uma análise e discussão da aplicabilidade do sistema kanban em uma empresa de calçados da Paraíba. Também Rentes et al. (2003) tratam da aplicação do kanban na indústria calçadista, em conjunto com outras ferramentas da Manufatura Enxuta, como por exemplo, o mapeamento do fluxo de valor. Ainda referente aos SCP, têm-se: o trabalho de Dias (2004), que, por meio de uma investigação empírica em uma empresa de calçados do Rio Grande do Sul, discute a aplicabilidade de um sistema de controle da produção no chão de fábrica no curto prazo; o trabalho de Cunha et al. (2003), que apresenta um estudo comparativo com relação à produtividade entre produção "puxada" e "empurrada" em uma empresa do setor calçadista . O estudo mostrou que a implementação da produção "puxada", com o controle de produção Kanban, proporcionou um elevado ganho de produtividade na operação de montagem. Ainda referente aos SCP, o trabalho de Bimbatti et al. (2005) analisa os bons resultados alcançados por uma empresa calçadista com a utilização conjunta do MRP/JIT. Benini Filho et al. (2001) estuda o uso de técnicas de planejamento e controle da produção nas empresas de Birigui-SP. Por fim, Bof et al. (2003) apresentam o desenvolvimento e a aplicação de um procedimento para medir e monitorar o tempo de fluxo e o inventário de uma empresa de calçados.

Em se tratando de estudos que focam os sistemas de produção, Tubino e Lopes (1996) apresentam, por meio de um estudo de caso, um comparativo entre o sistema de produção em massa e o sistema de produção enxuto. Os trabalhos de Ciosaki e Colenci Júnior (1998) e Ciosaki (1999) relatam os resultados alcançados após a adequação de princípios da filosofia Just in Time (JIT) à realidade de uma empresa calçadista. Sellitto (2000) analisa a aplicabilidade dos conceitos do Sistema Toyota de Produção na indústria calçadista. Outros artigos que enfocam as possibilidade que a produção enxuta abre para a gestão dos negócios na indústria calçadista são os trabalhos de Diedrich (2002), Sellitto (2001a), Sellitto (2001b) e Eidelwein et al. (2003). Tanto no trabalho de Sellitto (2000) quanto nos de Sellitto (2001a, 2001b), princípios da Teoria das Restrições (TOC) são descritos em conjunto com técnicas do Sistema Toyota de Produção. Leite (2003) adapta e aplica uma metodologia para identificar problemas e necessidades da área produtiva de pequenas e médias empresas calçadistas. 
Tabela 1. Classificação e codificação dos artigos da revisão sobre Gestão da Produção na indústria de calçados.

\begin{tabular}{|c|c|c|c|c|c|}
\hline $\begin{array}{l}\text { Artigo/ano de } \\
\text { publicação }\end{array}$ & $\begin{array}{c}\text { Classificação } \\
\text { quanto à origem }\end{array}$ & $\begin{array}{l}\text { Classificação } \\
\text { quanto às } \\
\text { grandes áreas }\end{array}$ & $\begin{array}{c}\text { Classificação } \\
\text { quanto às subáreas }\end{array}$ & $\begin{array}{c}\text { Classificação } \\
\text { quanto à } \\
\text { metodologia }\end{array}$ & $\begin{array}{r}\text { Classificação } \\
\text { quanto à fonte }\end{array}$ \\
\hline Nisanci e Sury (1980) & I & 1 & $1.1 ; 1.3$ & $\mathrm{E}$ & $\mathrm{R}$ \\
\hline Nisanci e Sury (1981) & I & 1 & $1.1 ; 1.3$ & $\mathrm{E}$ & $\mathrm{R}$ \\
\hline Arlington e Mylius (1986) & I & 8 & 8.1 & $\mathrm{E}$ & $\mathrm{R}$ \\
\hline Fernandes e Mattiuzzo (1986) & $\mathrm{N}$ & 7 & 7.3 & $\mathrm{E}$ & $\mathrm{R}$ \\
\hline Moreira (1987) & $\mathrm{N}$ & 8 & 8.1 & $\mathrm{~S}$ & $\mathrm{D}$ \\
\hline Ruas (1987) & $\mathrm{N}$ & 4,8 & $4.1 ; 8.2$ & $\mathrm{E}$ & $\mathrm{T}$ \\
\hline Ferraz (1988) & $\mathrm{N}$ & 6 & 6.1 & $\mathrm{E}$ & $\mathrm{D}$ \\
\hline Mores (1988) & $\mathrm{N}$ & 3 & 3.2 & $\mathrm{E}$ & $\mathrm{D}$ \\
\hline Ferreira (1989) & $\mathrm{N}$ & 1 & 1.4 & $\mathrm{E}$ & $\mathrm{D}$ \\
\hline Mazocato (1989a) & $\mathrm{N}$ & 7 & 7.5 & $\mathrm{E}$ & $\mathrm{R}$ \\
\hline Mazocato (1989b) & $\mathrm{N}$ & 7 & 7.5 & $\mathrm{E}$ & $\mathrm{D}$ \\
\hline Brenner (1990) & $\mathrm{N}$ & 7 & 7.1 & $\mathrm{E}$ & $\mathrm{D}$ \\
\hline Rocha (1990) & $\mathrm{N}$ & 8 & 8.2 & $\mathrm{E}$ & $\mathrm{D}$ \\
\hline Alves Filho (1991) & $\mathrm{N}$ & 8 & 8.2 & $\mathrm{E}$ & $\mathrm{T}$ \\
\hline Koppel (1992) & I & 9 & 9.3 & $\mathrm{E}$ & $\mathrm{R}$ \\
\hline Piccinini (1992) & $\mathrm{N}$ & 1 & 1.11 & $\mathrm{E}$ & $\mathrm{R}$ \\
\hline Reis (1992) & $\mathrm{N}$ & 8 & 8.1 & $\mathrm{E}$ & $\mathrm{D}$ \\
\hline Afonso (1993) & $\mathrm{N}$ & 7 & $7.1 ; 7.2$ & $\mathrm{~S}$ & $\mathrm{D}$ \\
\hline Cardoso (1993) & $\mathrm{N}$ & 5,8 & $5.2 ; 8.1$ & $\mathrm{E}$ & $\mathrm{D}$ \\
\hline Costa (1993) & $\mathrm{N}$ & 8 & $8.1 ; 8.2$ & $\mathrm{E}$ & $\mathrm{T}$ \\
\hline Gomes (1993) & $\mathrm{N}$ & 7 & 7.3 & $\mathrm{E}$ & $\mathrm{D}$ \\
\hline Rabellotti (1993) & I & 7 & $7.4 ; 7.6$ & $\mathrm{~S}$ & $\mathrm{R}$ \\
\hline Souza (1993) & $\mathrm{N}$ & 4 & $4.1 ; 4.4$ & $\mathrm{E}$ & $\mathrm{D}$ \\
\hline Orssatto (1994) & $\mathrm{N}$ & 7 & $7.1 ; 7.2$ & $\mathrm{E}$ & $\mathrm{D}$ \\
\hline Piccinini (1994) & $\mathrm{N}$ & 1,8 & $1.11 ; 8.2$ & $\mathrm{E}$ & $\mathrm{R}$ \\
\hline Reis (1994) & $\mathrm{N}$ & 7 & 7.1 & $\mathrm{E}$ & $\mathrm{T}$ \\
\hline Antunes (1995) & $\mathrm{N}$ & 2,4 & $2.1 ; 4.4$ & $\mathrm{E}$ & $\mathrm{L}$ \\
\hline Brandão (1995) & $\mathrm{N}$ & 7 & 7.2 & $\mathrm{E}$ & $\mathrm{L}$ \\
\hline Costa (1995) & $\mathrm{N}$ & 8 & 8.2 & $\mathrm{E}$ & $\mathrm{D}$ \\
\hline Cruz (1995) & $\mathrm{N}$ & 1 & 1.11 & $\mathrm{E}$ & $\mathrm{L}$ \\
\hline Fensterseifer e Gomes (1995a) & $\mathrm{N}$ & 7 & 7.6 & $\mathrm{E}$ & $\mathrm{L}$ \\
\hline Fensterseifer e Gomes (1995b) & $\mathrm{N}$ & 7 & $7.2 ; 7.3$ & $\mathrm{E}$ & $\mathrm{L}$ \\
\hline Knorringar (1995) & I & 7 & $7.4 ; 7.6$ & $\mathrm{~S}$ & $\mathrm{~L}$ \\
\hline Orssatto (1995) & $\mathrm{N}$ & 7 & 7.2 & $\mathrm{E}$ & $\mathrm{L}$ \\
\hline Piccinini (1995a) & $\mathrm{N}$ & 1,8 & $1.11 ; 8.2$ & $\mathrm{E}$ & $\mathrm{R}$ \\
\hline Piccinini (1995b) & $\mathrm{N}$ & 8 & $8.1 ; 8.2$ & $\mathrm{E}$ & $\mathrm{L}$ \\
\hline Rabellotti (1995) & $\mathrm{I}$ & 7 & 7.4 & $\mathrm{~S}$ & $\mathrm{R}$ \\
\hline Roesch (1995) & $\mathrm{N}$ & 4 & $4.1 ; 4.4$ & $\mathrm{E}$ & $\mathrm{L}$ \\
\hline Ruas (1995) & $\mathrm{N}$ & 7 & $7.4 ; 7.6$ & $\mathrm{~S}$ & $\mathrm{~L}$ \\
\hline Schmitz (1995) & I & 7 & 7.4 & $\mathrm{E}$ & $\mathrm{R}$ \\
\hline Silva e Fonseca (1995) & $\mathrm{N}$ & 7 & 7.4 & $\mathrm{E}$ & $\mathrm{L}$ \\
\hline Zawislak (1995) & $\mathrm{N}$ & 8 & $8.1 ; 8.2$ & $\mathrm{E}$ & $\mathrm{L}$ \\
\hline Benites (1996) & $\mathrm{N}$ & 3 & 3.2 & $\mathrm{E}$ & $\mathrm{D}$ \\
\hline Carvalho (1996) & $\mathrm{N}$ & 7 & 7.5 & $\mathrm{~S}$ & $\mathrm{D}$ \\
\hline Fanti et al. (1996) & I & 1 & 1.1 & $\mathrm{~T}$ & $\mathrm{R}$ \\
\hline Garcia (1996) & $\mathrm{N}$ & 7 & 7.4 & $\mathrm{E}$ & $\mathrm{D}$ \\
\hline Hollingum (1996a) & I & 1 & 1.6 & $\mathrm{E}$ & $\mathrm{R}$ \\
\hline Hollingum (1996b) & I & 1 & 1.6 & $\mathrm{E}$ & $\mathrm{R}$ \\
\hline Kochan (1996) & I & 1 & 1.6 & $\mathrm{E}$ & $\mathrm{R}$ \\
\hline Rooks (1996) & I & 1 & 1.6 & $\mathrm{E}$ & $\mathrm{R}$ \\
\hline Scarso e Bolisani (1996) & I & 8 & $8.1 ; 8.2$ & $\mathrm{E}$ & $\mathrm{R}$ \\
\hline Spencer Jr. (1996) & I & 1 & $1.2 ; 1.6$ & $\mathrm{E}$ & $\mathrm{R}$ \\
\hline
\end{tabular}


Tabela 1. (Continuação.)

\begin{tabular}{|c|c|c|c|c|c|}
\hline $\begin{array}{c}\text { Artigo/ano de } \\
\text { publicação }\end{array}$ & $\begin{array}{c}\text { Classificação } \\
\text { quanto à origem }\end{array}$ & $\begin{array}{c}\text { Classificação } \\
\text { quanto às } \\
\text { grandes áreas }\end{array}$ & $\begin{array}{c}\text { Classificação } \\
\text { quanto às subáreas }\end{array}$ & $\begin{array}{c}\text { Classificação } \\
\text { quanto à } \\
\text { metodologia }\end{array}$ & $\begin{array}{l}\text { Classificação } \\
\text { quanto à fonte }\end{array}$ \\
\hline Tubino e Lopes (1996) & $\mathrm{N}$ & 1 & $1.2 ; 1.4$ & $\mathrm{E}$ & $\mathrm{C} 1$ \\
\hline Azevedo (1997) & $\mathrm{N}$ & 3 & 3.2 & $\mathrm{E}$ & $\mathrm{D}$ \\
\hline Faria (1997) & $\mathrm{N}$ & 4 & 4.1 & $\mathrm{E}$ & $\mathrm{D}$ \\
\hline Garcia (1997) & $\mathrm{N}$ & 7 & 7.3 & $\mathrm{E}$ & $\mathrm{D}$ \\
\hline Harfield e Hamilton (1997) & I & 7 & 7.2 & $\mathrm{E}$ & $\mathrm{R}$ \\
\hline Murari (1997) & $\mathrm{N}$ & 1,6 & $1.1 ; 6.1$ & $\mathrm{E}$ & $\mathrm{D}$ \\
\hline Santos et al. (1997) & $\mathrm{N}$ & 1 & 1.11 & $\mathrm{E}$ & $\mathrm{C} 1$ \\
\hline Viegas (1997) & $\mathrm{N}$ & 10 & 10.4 & $\mathrm{E}$ & $\mathrm{D}$ \\
\hline Carvalho (1998a) & $\mathrm{N}$ & 1 & 1.11 & $\mathrm{E}$ & $\mathrm{C} 1$ \\
\hline Carvalho (1998b) & $\mathrm{N}$ & 1 & 1.11 & $\mathrm{E}$ & $\mathrm{D}$ \\
\hline Ciosaki e Colenci Júnior (1998) & $\mathrm{N}$ & 1 & 1.2 & $\mathrm{E}$ & $\mathrm{C} 1$ \\
\hline Navarro (1998) & $\mathrm{N}$ & 4 & 4.1 & $\mathrm{E}$ & $\mathrm{T}$ \\
\hline Pereira (1998) & $\mathrm{N}$ & 1 & 1.11 & $\mathrm{E}$ & $\mathrm{T}$ \\
\hline Rabellotti (1998) & I & 7 & 7.4 & $\mathrm{~S}$ & $\mathrm{R}$ \\
\hline Salomão (1998) & $\mathrm{N}$ & 1,7 & $1.11 ; 7.3$ & $\mathrm{E}$ & $\mathrm{D}$ \\
\hline Salomão e Alves Filho (1998) & $\mathrm{N}$ & 1,7 & $1.11 ; 7.3$ & $\mathrm{E}$ & $\mathrm{C} 1$ \\
\hline Santos (1998) & $\mathrm{N}$ & 5 & 5.2 & $\mathrm{E}$ & $\mathrm{D}$ \\
\hline Woodruff (1998) & I & 7 & 7.4 & $\mathrm{~S}$ & $\mathrm{R}$ \\
\hline Albuquerque (1999) & $\mathrm{N}$ & 7 & $7.2 ; 7.3$ & $\mathrm{E}$ & $\mathrm{D}$ \\
\hline Albuquerque et al. (1999) & $\mathrm{N}$ & 1 & $1.1 ; 1.2$ & $\mathrm{E}$ & $\mathrm{C} 1$ \\
\hline Ciosaki (1999) & $\mathrm{N}$ & 1 & $1.2 ; 1.11$ & $\mathrm{E}$ & $\mathrm{D}$ \\
\hline Hsing (1999) & I & 7 & $7.4 ; 7.6$ & $\mathrm{~S}$ & $\mathrm{R}$ \\
\hline Perry et al. (1999) & I & 7 & 7.6 & $\mathrm{E}$ & $\mathrm{R}$ \\
\hline Schmitz (1999) & I & 7 & 7.6 & $\mathrm{~S}$ & $\mathrm{R}$ \\
\hline Silva (1999) & $\mathrm{N}$ & 9 & $9.1 ; 9.4$ & $\mathrm{~S}$ & $\mathrm{D}$ \\
\hline Corrêa (2000) & $\mathrm{N}$ & 7 & 7.6 & $\mathrm{E}$ & $\mathrm{D}$ \\
\hline Fernandes e Murari (2000a) & $\mathrm{N}$ & 6 & 6.1 & $\mathrm{E}$ & $\mathrm{C} 1$ \\
\hline Fernades e Murari (2000b) & $\mathrm{N}$ & 7 & 7.3 & $\mathrm{E}$ & $\mathrm{R}$ \\
\hline Martins (2000) & $\mathrm{N}$ & 1 & 1.10 & $\mathrm{E}$ & $\mathrm{C} 3$ \\
\hline Perez-Aleman (2000) & I & 7 & $7.4 ; 7.6$ & $\mathrm{~S}$ & $\mathrm{R}$ \\
\hline Ribeiro (2000) & $\mathrm{N}$ & 1 & 1.11 & $\mathrm{E}$ & $\mathrm{T}$ \\
\hline Sellitto (2000) & $\mathrm{N}$ & 1 & 1.2 & $\mathrm{E}$ & $\mathrm{R}$ \\
\hline Tomelin (2000) & $\mathrm{N}$ & 7 & $7.4 ; 7.6$ & $\mathrm{E}$ & $\mathrm{D}$ \\
\hline Vecchio (2000) & $\mathrm{N}$ & 7 & $7.1 ; 7.4$ & $\mathrm{E}$ & $\mathrm{R}$ \\
\hline Albuquerque e Silva (2001) & $\mathrm{N}$ & 7 & 7.3 & $\mathrm{E}$ & $\mathrm{R}$ \\
\hline Arce et al. (2001) & $\mathrm{N}$ & 8,9 & $8.1 ; 9.3$ & $\mathrm{E}$ & $\mathrm{C} 1$ \\
\hline Benini Filho et al. (2001) & $\mathrm{N}$ & 1 & 1.1 & $\mathrm{~S}$ & $\mathrm{C} 3$ \\
\hline Bimbatti (2001) & $\mathrm{N}$ & 7 & 7.4 & $\mathrm{E}$ & $\mathrm{C} 3$ \\
\hline Cavenaghi (2001) & $\mathrm{N}$ & 7 & $7.2 ; 7.3$ & $\mathrm{E}$ & $\mathrm{T}$ \\
\hline Debiasi (2001) & $\mathrm{N}$ & 7 & 7.4 & $\mathrm{E}$ & $\mathrm{D}$ \\
\hline Estrela (2001) & $\mathrm{N}$ & 1 & 1.5 & $\mathrm{E}$ & $\mathrm{R}$ \\
\hline Fusco e Sacomano (2001a) & $\mathrm{N}$ & 7 & $7.4 ; 7.6$ & $\mathrm{~S}$ & $\mathrm{C} 1$ \\
\hline Fusco e Sacomano (2001b) & $\mathrm{N}$ & 7 & 7.6 & $\mathrm{~S}$ & $\mathrm{C} 3$ \\
\hline Garcia (2001) & $\mathrm{N}$ & 7 & $7.4 ; 7.6$ & $\mathrm{E}$ & $\mathrm{T}$ \\
\hline Henriques (2001) & $\mathrm{N}$ & 8 & 8.2 & $\mathrm{E}$ & $\mathrm{D}$ \\
\hline Lima e Martins (2001) & $\mathrm{N}$ & 7 & $7.2 ; 7.4$ & $\mathrm{E}$ & $\mathrm{C} 1$ \\
\hline Motta (2001) & $\mathrm{N}$ & 7 & $7.4 ; 7.6$ & $\mathrm{E}$ & $\mathrm{C} 3$ \\
\hline Pereira (2001) & $\mathrm{N}$ & 7 & 7.4 & $\mathrm{E}$ & $\mathrm{T}$ \\
\hline Perry e Sohal (2001) & I & 7 & 7.6 & $\mathrm{E}$ & $\mathrm{R}$ \\
\hline Rehfeldt (2001) & $\mathrm{N}$ & 6 & 6.1 & $\mathrm{~T}$ & $\mathrm{D}$ \\
\hline Ruppenthal (2001) & $\mathrm{N}$ & 7,10 & $7.2 ; 10.1 ; 10.2$ & $\mathrm{E}$ & $\mathrm{T}$ \\
\hline Sellitto (2001a) & $\mathrm{N}$ & 1 & 1.2 & E & $\mathrm{R}$ \\
\hline
\end{tabular}


Tabela 1. (Continuação.)

\begin{tabular}{|c|c|c|c|c|c|}
\hline $\begin{array}{l}\text { Artigo/ano de } \\
\text { publicação }\end{array}$ & $\begin{array}{c}\text { Classificação } \\
\text { quanto à origem }\end{array}$ & $\begin{array}{c}\text { Classificação } \\
\text { quanto às } \\
\text { grandes áreas }\end{array}$ & $\begin{array}{c}\text { Classificação } \\
\text { quanto às subáreas }\end{array}$ & $\begin{array}{c}\text { Classificação } \\
\text { quanto à } \\
\text { metodologia }\end{array}$ & $\begin{array}{l}\text { Classificação } \\
\text { quanto à fonte }\end{array}$ \\
\hline Sellitto (2001b) & $\mathrm{N}$ & 1 & 1.2 & $\mathrm{E}$ & $\mathrm{R}$ \\
\hline Silva (2001) & $\mathrm{N}$ & 1,4 & $1.4 ; 4.1 ; 4.3$ & $\mathrm{E}$ & $\mathrm{C} 3$ \\
\hline Souza e Fernandes (2001) & $\mathrm{N}$ & 8 & 8.3 & $\mathrm{E}$ & $\mathrm{R}$ \\
\hline Vendrameto et al. (2001) & $\mathrm{N}$ & 7 & 7.6 & $\mathrm{E}$ & $\mathrm{C} 1$ \\
\hline Bimbatti e Laurindo (2002) & $\mathrm{N}$ & 9 & $9.1 ; 9.3$ & $\mathrm{~S}$ & $\mathrm{C} 3$ \\
\hline Bimbatti e Toledo (2002) & $\mathrm{N}$ & 7 & 7.2 & $\mathrm{E}$ & $\mathrm{C} 2$ \\
\hline Boscolo (2002) & $\mathrm{N}$ & 4 & $4.3 ; 4.5 ; 4.6$ & $\mathrm{E}$ & $\mathrm{D}$ \\
\hline Correia (2002) & $\mathrm{N}$ & 7 & 7.4 & $\mathrm{E}$ & $\mathrm{D}$ \\
\hline Cunha et al. (2002) & $\mathrm{N}$ & 1 & $1.2 ; 1.4$ & $\mathrm{E}$ & $\mathrm{C} 1$ \\
\hline Diedrich (2002) & $\mathrm{N}$ & 1 & $1.2 ; 1.5$ & $\mathrm{E}$ & $\mathrm{D}$ \\
\hline Estrela et al. (2002) & $\mathrm{N}$ & 3 & 3.2 & $\mathrm{E}$ & $\mathrm{C} 1$ \\
\hline Francischini e Azevedo (2002) & $\mathrm{N}$ & 1,7 & $1.5 ; 7.2$ & $\mathrm{E}$ & $\mathrm{C} 1$ \\
\hline Kim et al. (2002) & I & 1 & 1.1 & $\mathrm{E}$ & $\mathrm{R}$ \\
\hline Kinloch (2002) & $\mathrm{N}$ & 7 & $7.4 ; 7.6$ & $\mathrm{E}$ & $\mathrm{D}$ \\
\hline Lima (2002) & $\mathrm{N}$ & 2 & 2.1 & $\mathrm{E}$ & $\mathrm{D}$ \\
\hline Lima e Martins (2002) & $\mathrm{N}$ & 2 & 2.1 & $\mathrm{E}$ & $\mathrm{C} 2$ \\
\hline Orssatto (2002) & $\mathrm{N}$ & 7 & $7.2 ; 7.4$ & $\mathrm{E}$ & $\mathrm{T}$ \\
\hline Pereira e Brunstein (2002a) & $\mathrm{N}$ & 7 & $7.2 ; 7.4$ & $\mathrm{E}$ & $\mathrm{C} 1$ \\
\hline Pereira e Brunstein (2002b) & $\mathrm{N}$ & 7 & $7.2 ; 7.4$ & $\mathrm{E}$ & $\mathrm{O}$ \\
\hline Renner (2002) & $\mathrm{N}$ & 4 & $4.3 ; 4.5 ; 4.6$ & $\mathrm{E}$ & $\mathrm{D}$ \\
\hline Silva (2002a) & $\mathrm{N}$ & 9 & 9.1 & $\mathrm{E}$ & $\mathrm{D}$ \\
\hline Silva (2002b) & $\mathrm{N}$ & 1,9 & $1.1 ; 9.2$ & $\mathrm{~S}$ & $\mathrm{D}$ \\
\hline Silva (2002c) & $\mathrm{N}$ & 1 & 1.10 & $\mathrm{E}$ & $\mathrm{D}$ \\
\hline Silva e Fernandes (2002a) & $\mathrm{N}$ & 9 & $9.2 ; 9.3 ; 9.4$ & $\mathrm{E}$ & $\mathrm{C} 2$ \\
\hline Silva e Fernades (2002b) & $\mathrm{N}$ & 1 & 1.1 & $\mathrm{E}$ & $\mathrm{R}$ \\
\hline Souza (2002) & $\mathrm{N}$ & 1,9 & $1.1 ; 9.3$ & $\mathrm{P}$ & $\mathrm{D}$ \\
\hline Suzigan et al. (2002) & $\mathrm{N}$ & 7 & 7.6 & $\mathrm{E}$ & $\mathrm{O}$ \\
\hline Tristão (2002) & $\mathrm{N}$ & 7 & 7.6 & $\mathrm{E}$ & $\mathrm{C} 2$ \\
\hline Woodruff (2002) & I & 7 & 7.6 & $\mathrm{~S}$ & $\mathrm{R}$ \\
\hline Biehl e Mosele (2003) & $\mathrm{N}$ & 4 & $4.1 ; 4.4$ & $\mathrm{E}$ & $\mathrm{C} 1$ \\
\hline Bimbatti et al. (2003) & $\mathrm{N}$ & 7 & 7.2 & $\mathrm{E}$ & $\mathrm{C} 3$ \\
\hline Blos (2003) & $\mathrm{N}$ & 1,8 & $1.4 ; 8.2$ & $\mathrm{E}$ & $\mathrm{D}$ \\
\hline Bof et al. (2003) & $\mathrm{N}$ & 1 & $1.1 ; 1.2$ & $\mathrm{E}$ & $\mathrm{C} 1$ \\
\hline Cezar et al. (2003) & $\mathrm{N}$ & 4 & 4.2 & $\mathrm{E}$ & $\mathrm{C} 1$ \\
\hline Crocco et al. (2003) & $\mathrm{N}$ & 7 & 7.4 & $\mathrm{E}$ & $\mathrm{R}$ \\
\hline Cunha (2003) & $\mathrm{N}$ & 1,8 & $1.5 ; 8.1$ & $\mathrm{E}$ & $\mathrm{C} 1$ \\
\hline Cunha et al. (2003) & $\mathrm{N}$ & 1 & $1.1 ; 1.4$ & $\mathrm{E}$ & $\mathrm{C} 1$ \\
\hline Eidelwein et al. (2003) & $\mathrm{N}$ & 1 & 1.2 & $\mathrm{E}$ & $\mathrm{C} 1$ \\
\hline Francischini e Azevedo (2003a) & $\mathrm{N}$ & 7 & $7.2 ; 7.3$ & $\mathrm{E}$ & $\mathrm{C} 1$ \\
\hline Francischini e Azevedo (2003b) & $\mathrm{N}$ & 7 & $7.1 ; 7.2$ & $\mathrm{E}$ & $\mathrm{R}$ \\
\hline Guimarães e Renner (2003) & $\mathrm{N}$ & 4 & $4.5 ; 4.6$ & $\mathrm{E}$ & $\mathrm{C} 1$ \\
\hline Hernandez (2003) & $\mathrm{N}$ & 2 & 2.1 & $\mathrm{E}$ & $\mathrm{D}$ \\
\hline Kmita et al. (2003) & $\mathrm{N}$ & 1,4 & $1.4 ; 4.5 ; 4.6$ & $\mathrm{E}$ & $\mathrm{C} 1$ \\
\hline Lages (2003) & $\mathrm{N}$ & 7 & 7.4 & $\mathrm{E}$ & $\mathrm{T}$ \\
\hline Leite (2003) & $\mathrm{N}$ & 1 & 1.2 & $\mathrm{~S}$ & $\mathrm{D}$ \\
\hline Leite e Fernandes (2003a) & $\mathrm{N}$ & 1 & $1.2 ; 1.6$ & $\mathrm{~S}$ & $\mathrm{C} 3$ \\
\hline Leite e Fernandes (2003b) & $\mathrm{N}$ & 7 & 7.3 & $\mathrm{E}$ & $\mathrm{R}$ \\
\hline Lemos (2003) & $\mathrm{N}$ & 7 & 7.4 & $\mathrm{E}$ & $\mathrm{R}$ \\
\hline Mollo Neto e Vendrametto (2003) & $\mathrm{N}$ & 8 & 8.1 & $\mathrm{E}$ & $\mathrm{C} 2$ \\
\hline Motta e Escrivão Filho (2003) & $\mathrm{N}$ & 1,8 & $1.2 ; 8.3$ & $\mathrm{E}$ & $\mathrm{C} 3$ \\
\hline Nadaleto (2003) & $\mathrm{N}$ & 7 & 7.3 & $\mathrm{E}$ & $\mathrm{D}$ \\
\hline Navarro (2003) & $\mathrm{N}$ & 4 & $4.1 ; 4.5$ & $\mathrm{E}$ & $\mathrm{O}$ \\
\hline
\end{tabular}


Tabela 1. (Continuação.)

\begin{tabular}{|c|c|c|c|c|c|}
\hline $\begin{array}{l}\text { Artigo/ano de } \\
\text { publicação }\end{array}$ & $\begin{array}{c}\text { Classificação } \\
\text { quanto à origem }\end{array}$ & $\begin{array}{l}\text { Classificação } \\
\text { quanto às } \\
\text { grandes áreas }\end{array}$ & $\begin{array}{c}\text { Classificação } \\
\text { quanto às subáreas }\end{array}$ & $\begin{array}{c}\text { Classificação } \\
\text { quanto à } \\
\text { metodologia }\end{array}$ & $\begin{array}{l}\text { Classificação } \\
\text { quanto à fonte }\end{array}$ \\
\hline Pace et al. (2003) & $\mathrm{N}$ & 7 & 7.1 & $\mathrm{E}$ & $\mathrm{C} 2$ \\
\hline Pereira e Brunstein (2003) & $\mathrm{N}$ & 7 & $7.2 ; 7.4$ & $\mathrm{E}$ & $\mathrm{C} 1$ \\
\hline Pinotti (2003) & $\mathrm{N}$ & 5 & $5.2 ; 5.4$ & $\mathrm{P}$ & $\mathrm{D}$ \\
\hline Rentes et al. (2003) & $\mathrm{N}$ & 1 & $1.1 ; 1.2$ & $\mathrm{E}$ & $\mathrm{C} 3$ \\
\hline Rhoden (2003) & $\mathrm{N}$ & 7 & 7.2 & $\mathrm{E}$ & $\mathrm{R}$ \\
\hline Santos et al. (2003) & $\mathrm{N}$ & 1 & $1.4 ; 1.12$ & $\mathrm{E}$ & $\mathrm{C} 1$ \\
\hline Sevegnani e Sacomano (2003a) & $\mathrm{N}$ & 1,8 & $1.5 ; 8.1$ & $\mathrm{E}$ & $\mathrm{C} 1$ \\
\hline Sevegnani e Sacomano (2003b) & $\mathrm{N}$ & 1,8 & $1.5 ; 8.1$ & $\mathrm{E}$ & $\mathrm{C} 3$ \\
\hline Silva e Fernandes (2003) & $\mathrm{N}$ & 9 & 9.1 & $\mathrm{E}$ & $\mathrm{C} 2$ \\
\hline Vargas e Alievi (2003) & $\mathrm{N}$ & 7 & 7.4 & $\mathrm{E}$ & $\mathrm{R}$ \\
\hline Wu et al. (2003) & $\mathrm{I}$ & 6 & 6.1 & $\mathrm{~T}$ & $\mathrm{R}$ \\
\hline Alves et al. (2004) & $\mathrm{N}$ & 7 & $7.4 ; 7.6$ & $\mathrm{E}$ & $\mathrm{C} 3$ \\
\hline Anzanello e Fogliatto (2004) & $\mathrm{N}$ & 1 & 1.11 & $\mathrm{E}$ & $\mathrm{C} 1$ \\
\hline Barnett et al. (2004) & I & 1 & 1.1 & $\mathrm{P}$ & $\mathrm{R}$ \\
\hline Castro et al. (2004) & $\mathrm{N}$ & 9 & $9.1 ; 9.2$ & $\mathrm{E}$ & $\mathrm{C} 1$ \\
\hline Dias (2004) & $\mathrm{N}$ & 1 & $1.1 ; 1.2$ & $\mathrm{E}$ & $\mathrm{C} 1$ \\
\hline Dulio e Boër (2004) & I & 1 & 1.6 & $\mathrm{E}$ & $\mathrm{R}$ \\
\hline Estivalet et al. (2004) & $\mathrm{N}$ & 4 & 4.6 & $\mathrm{E}$ & $\mathrm{C} 1$ \\
\hline Godinho Filho (2004) & $\mathrm{N}$ & 1,7 & $1.1 ; 7.3$ & $\mathrm{E}$ & $\mathrm{T}$ \\
\hline Hansen et al. (2004) & $\mathrm{N}$ & 7 & $7.4 ; 7.6$ & $\mathrm{~S}$ & $\mathrm{C} 1$ \\
\hline Hanzl-Weib (2004) & I & 7 & 7.1 & $\mathrm{E}$ & $\mathrm{O}$ \\
\hline Lopes e Fernades (2004) & $\mathrm{N}$ & 3 & 3.2 & $\mathrm{E}$ & $\mathrm{R}$ \\
\hline Marasea et al. (2004) & $\mathrm{N}$ & 4 & 4.4 & $\mathrm{E}$ & $\mathrm{C} 3$ \\
\hline Narain et al. (2004) & I & 1 & $1.2 ; 1.5$ & $\mathrm{E}$ & $\mathrm{R}$ \\
\hline Pegatin e Silva (2004) & $\mathrm{N}$ & 4 & $4.3 ; 4.5$ & $\mathrm{E}$ & $\mathrm{C} 3$ \\
\hline Severo et al. (2004) & $\mathrm{N}$ & 2,7 & $2.1 ; 7.2$ & $\mathrm{E}$ & $\mathrm{C} 1$ \\
\hline Silva e Fernandes (2004) & $\mathrm{N}$ & 9 & $9.1 ; 9.2$ & $\mathrm{E}$ & $\mathrm{R}$ \\
\hline Silva et al. (acessado em 2004) & $\mathrm{N}$ & 3 & 3.2 & $\mathrm{E}$ & $\mathrm{O}$ \\
\hline Sousa et al. (2004) & $\mathrm{N}$ & 1,8 & $1.2 ; 8.1$ & $\mathrm{E}$ & $\mathrm{C} 3$ \\
\hline Vasconcelos e Ferreira (2004) & $\mathrm{N}$ & 10 & $10.1 ; 10.4$ & $\mathrm{E}$ & $\mathrm{C} 1$ \\
\hline Zangiacomi et al. (2004) & I & 1 & 1.1 & $\mathrm{P}$ & $\mathrm{R}$ \\
\hline Zanini e Oliveira (2004) & $\mathrm{N}$ & 7 & 7.2 & $\mathrm{E}$ & $\mathrm{C} 1$ \\
\hline Alves e Braga Filho (2005) & $\mathrm{N}$ & 7 & 7.1 & $\mathrm{R}$ & $\mathrm{C} 3$ \\
\hline Anzanello e Fogliatto (2005) & $\mathrm{N}$ & 1 & 1.11 & $\mathrm{E}$ & $\mathrm{R}$ \\
\hline Bimbatti et al. (2005) & $\mathrm{N}$ & 1 & 1.1 & $\mathrm{E}$ & $\mathrm{C} 3$ \\
\hline Buxey (2005) & I & 7 & $7.1 ; 7.4$ & $\mathrm{~S}$ & $\mathrm{R}$ \\
\hline Ceroni e Nof (2005) & I & 7 & 7.6 & $\mathrm{E}$ & $\mathrm{R}$ \\
\hline Ciappei e Simoni (2005) & I & 5 & 5.2 & $\mathrm{~S}$ & $\mathrm{R}$ \\
\hline Giusti (2005) & $\mathrm{N}$ & 7 & 7.2 & $\mathrm{E}$ & $\mathrm{D}$ \\
\hline Holanda et al. (2005) & $\mathrm{N}$ & 9 & 9.4 & $\mathrm{~S}$ & $\mathrm{C} 3$ \\
\hline Linda e Guimarães (2005) & $\mathrm{N}$ & 4 & 4.2 & $\mathrm{~S}$ & $\mathrm{C} 1$ \\
\hline Machado et al.(2005) & $\mathrm{N}$ & 7 & 7.3 & $\mathrm{E}$ & $\mathrm{C} 3$ \\
\hline Pinto e Schramm (2005) & $\mathrm{N}$ & 6 & 6.1 & $\mathrm{E}$ & $\mathrm{C} 1$ \\
\hline Rocha e Elias (2005) & $\mathrm{N}$ & 2 & $2.3 ; 2.4$ & $\mathrm{~S}$ & $\mathrm{C} 3$ \\
\hline Silva (2005) & $\mathrm{N}$ & 8 & 8.1 & $\mathrm{E}$ & $\mathrm{C} 3$ \\
\hline Sousa et al. (2005) & $\mathrm{N}$ & 7 & $7.4 ; 7.6$ & $\mathrm{E}$ & $\mathrm{R}$ \\
\hline Bamford e Land (2006) & I & 2 & 2.1 & $\mathrm{P}$ & $\mathrm{R}$ \\
\hline Machado Neto (2006) & $\mathrm{N}$ & 7 & 7.5 & $\mathrm{~S}$ & $\mathrm{~T}$ \\
\hline Scott (2006) & I & 7 & 7.4 & $\mathrm{E}$ & $\mathrm{R}$ \\
\hline Bertololini et al. (2007) & I & 7 & 7.6 & $\mathrm{E}$ & $\mathrm{R}$ \\
\hline Bimbatti (2007) & $\mathrm{N}$ & 7 & 7.2 & $\mathrm{E}$ & $\mathrm{T}$ \\
\hline Abrunhosa e Sá (2008) & I & 2,8 & $2.1 ; 8.1$ & $\mathrm{~S}$ & $\mathrm{R}$ \\
\hline Chituc et al. (2008) & I & 8 & 8.1 & $\mathrm{E}$ & $\mathrm{R}$ \\
\hline
\end{tabular}


Dentro da subárea projeto de fábrica e layout tem-se o trabalho de Ferreira (1989) que verifica a evolução da arquitetura industrial da cidade de Franca a partir do surgimento da indústria coureiro-calçadista. Cunha et al. (2002) e Santos et al. (2003) tratam de objetivos comuns: melhoria da produtividade e aperfeiçoamento do sistema produtivo a partir de reformulações no arranjo físico de instalações fabris.

Dois trabalhos, Estrela (2001) e Narain et al. (2004), enfocam a subárea processos de fabricação. Estrela (2001) trata da identificação dos tipos de perdas internas que pode haver nas empresas de curtume. Narain et al. (2004) realiza um estudo de caso em uma grande organização indiana produtora de calçados a qual utiliza o sistema de manufatura flexível.

Com o foco em automação, os trabalhos de Hollingum (1996a, 1996b) descrevem, respectivamente, inovações em equipamentos avançados tecnologicamente para a produção de calçados e o mercado consumidor de máquinas de costura automáticas. Kochan (1996) descreve as características de um equipamento para a indústria de calçados e atribui o crescimento da competitividade internacional nessa indústria à robótica. Rooks (1996) demonstra os benefícios alcançados por duas empresas fabricantes de calçados após a implantação da automação industrial. Spencer Jr. (1996) relaciona a inserção de equipamentos avançados tecnologicamente no mercado com o advento do sistema de manufatura ágil dentro da indústria de calçados. Dulio e Boër (2004) descrevem as características de um modelo de fábrica de calçados altamente integrada, com altos níveis de automação nos processos. Finalmente, Leite e Fernandes (2003a) analisam empresas no polo calçadista de Birigui em termos de automação e de sistemas informatizados para a Gestão da Produção.

Focando a logística temos três trabalhos. Silva (2002c) propõe um modelo de avaliação do desempenho na aquisição dos principais itens de consumo para a indústria calçadista. Martins (2000) também discute como as atividades de logística podem contribuir para o sucesso empresarial na área. Kim et al. (2002) propõem um sistema para o gerenciamento de ordens e distribuição de produtos para ser implementado no ambiente da cadeia de suprimentos de uma empresa calçadista.

Com relação à organização do trabalho dentro da gerência da produção, Piccinini (1992) faz uma análise do impacto da mudança das formas de organização do trabalho em empresas de médio e grande porte em dois importantes polos calçadistas: a região do Vale dos Sinos e Franca. Cruz (1995) investiga, por meio de estudos de caso, as alterações que vêm ocorrendo na qualificação da mão de obra em decorrência da implantação de novos paradigmas de produção, tais como o just in time. Carvalho (1998a,b) analisam a gestão da mão de obra em sete microempresas em um polo calçadista do Nordeste. Pereira (1998) estuda aspectos da subcontratação do trabalho em um polo calçadista da região Sul do Brasil (Vale dos Sinos). Este autor conclui que a subcontratação neste polo, ao invés de criar um ambiente favorável à inovação e à qualificação dos trabalhadores, revelou-se apenas um artifício para a redução de custos do trabalho pelas empresas. Já Santos et al. (1997) fazem uma análise da capacidade tecnológica de uma empresa do setor calçadista localizada na região do Vale dos Sinos e apresenta as vantagens da subcontratação. Ribeiro (2000) analisa os caminhos da reestruturação produtiva na indústria calçadista brasileira e seus impactos no trabalho. Por fim, Anzanello e Fogliatto $(2004,2005)$ propõem um procedimento baseado na utilização de curvas de aprendizagem para a alocação de produtos a equipes de trabalhadores.

\subsubsection{Artigos referentes à qualidade}

Dentro dessa área encontram-se cinco artigos, sendo que quatro enfocam a gestão da qualidade. Lima (2002) e Lima e Martins (2002) realizam um diagnóstico do estágio da gestão da qualidade na indústria calçadista de Franca-SP. Comprova-se o fato de que as empresas desse polo calçadista ainda se encontram no estágio inicial da gestão da qualidade. Hernandez (2003) traz um estudo que procura evidenciar a compatibilidade entre a implantação de programas de qualidade e as práticas de terceirização. Bamford e Land (2006) investigam aspectos relacionados às medidas de custo para a qualidade e como elas podem ser úteis na tomada de decisão e na implementação de melhorias.

Com relação à subárea normalização e certificação para a qualidade, Rocha e Elias (2005) analisam a efetividade dos atendimentos tecnológicos feitos pelo IPT (Instituto de Pesquisas Tecnológicas de São Paulo) em empresas calçadistas do Nordeste.

\subsubsection{Artigos referentes à gestão econômica}

Dentro dessa área encontram-se 7 artigos, sendo que todos enfocam a gestão de custos. Mores (1988) investiga o sistema de contabilidade de formação de custos indiretos das empresas calçadistas da região do Vale dos Sinos. Estrela et al. (2002) constatam a ineficácia dos sistemas de controle de custos e formação de preços de venda do setor calçadista da Paraíba. Silva et al. (acessado em 2004) também encontram falhas nos critérios adotados pela contabilidade de custos para custeamento dos produtos em duas empresas calçadistas de Franca-SP. Já Benites (1996) desenvolve um modelo de custeio por atividades de manufatura de modo a alocar os custos indiretos aos produtos fabricados na indústria calçadista. Azevedo (1997) traz um estudo dos sistemas de custo para decisão. Por fim, Lopes e Fernandes (2004) propõem uma abordagem hierárquica para escolher o sistema de custeio em função principalmente do tipo de decisões gerenciais que serão suportadas pelo sistema de custeio. 


\subsubsection{Artigos referentes a ergonomia e segurança do trabalho}

Com relação à organização do trabalho, o estudo de Faria (1997) aborda a prática da "autogestão" por parte dos trabalhadores de uma empresa de calçados da cidade de Franca-SP. Roesch (1995) discute as implicações da utilização de sistemas flexíveis de trabalho sobre a gestão dos recursos humanos, ou seja, como buscar o comprometimento, a participação e o investimento na qualificação dos trabalhadores. Biehl e Mosele (2003) fazem uma análise das células de produção e dos grupos de trabalho e das suas implicações na motivação e satisfação dos operários. Já Navarro (1998) objetiva compreender os impactos sobre a força de trabalho empregada pelo setor calçadista de Franca-SP à medida que se observa uma redução do emprego formal e uma tendência de crescimento do emprego informal.

Focando a ergonomia do produto, Cezar et al. (2003) demonstram o que se tem feito, atualmente, para avaliar o conforto em calçados. Linden e Guimarães (2005) contribuem para a compreensão dos fatores que afetam o uso do calçado feminino de salto alto e bico fino.

Focando a psicologia do trabalho, Souza (1993) estuda a vivência das relações de trabalho no setor de calçados. Marasea et al. (2004) abordam a percepção da qualidade de vida no trabalho por parte dos funcionários de uma empresa de calçados.

Dentro da subárea segurança do trabalho e riscos industriais, Boscolo (2002) analisa as ações em saúde ocupacional de empresas do ramo calçadista diante do crescimento de lesões por esforços repetitivos (LER) e de distúrbios osteomusculares relacionados ao trabalho (DORT). Já Renner (2002) e Guimarães e Renner (2003) analisam os custos posturais nos postos de trabalho do setor de costura de empresas calçadistas. Navarro (2003) traz um estudo que analisa a repercussão sobre a saúde dos trabalhadores frente à intensificação do trabalho em empresas de calçados de Franca-SP. Pegatin e Silva (2004) utilizam-se da análise ergonômica do trabalho (AET) a fim de otimizar a qualidade de vida no trabalho.

Em se tratando de biomecânica ocupacional, Estivalet et al. (2004) apresentam os resultados advindos da avaliação ergonômica de um modelo de máquina de costura utilizada para confecção de calçados.

\subsubsection{Artigos referentes à engenharia do produto}

Nesta área foram encontrados três trabalhos e todos focando o planejamento e projeto do produto. Tanto o trabalho de Santos (1998) como o de Pinnotti (2003) estudam a gestão do processo de desenvolvimento de produtos sob o enfoque da qualidade. Ambos os trabalhos ressaltam que tal prática pode-se tornar o diferencial que irá posicionar e destacar um determinado produto no mercado. Ciappei e Simoni (2005) identificam vários fatores de sucesso alcançados com a adoção de práticas de desenvolvimento de novos produtos.

\subsubsection{Artigos referentes à pesquisa operacional}

Nesta área foram encontrados cinco trabalhos, todos com o foco em programação matemática. Ferraz (1988) aplica a programação dinâmica para solucionar o problema de controle de estoques de uma grande loja de calçados. Rehfeldt (2001) mostra em seu estudo uma heurística capaz de reduzir a quantidade de fôrmas na indústria calçadista. Wu et al. (2003) propõem um algoritmo heurístico híbrido para ser utilizado na alocação de partes com dimensões irregulares em uma chapa, caracterizando um problema de corte bidimensional. Fernandes e Murari (2000a) apresentam uma metodologia para cortar peças de sapatos de couro baseada em procedimentos heurísticos assim como no uso de sistemas CAD/CAM. E, por fim, Pinto e Schramm (2005) desenvolvem um modelo de programação matemática que maximiza o lucro de uma empresa calçadista.

\subsubsection{Artigos referentes a estratégia e organizações}

Com relação à avaliação de mercado, o trabalho de Brenner (1990) descreve a evolução histórica do setor calçadista no Brasil, visando aumentar o conhecimento das razões de sucesso da indústria de calçados no País. Reis (1994) analisa o comportamento da indústria brasileira de calçados no transcorrer dos anos 80 e sua inserção em nível de mercado internacional. O artigo de Vecchio (2000) busca mostrar as fragilidades do setor coureiro-calçadista do Rio Grande do Sul alavancadas pela globalização do mercado e pela combinação de fatores que ocorreram após o ano de 1993. Já o estudo de Alves e Braga Filho (2005) caracteriza o fenômeno da reestruturação produtiva ao longo dos anos 90 e o seu efeito sobretudo no que tange à precarização do trabalho. Pace et al. (2003) analisam o impacto da desvalorização da moeda brasileira em 1999 no nível de desemprego do setor calçadista argentino. Ainda nesta subárea, o trabalho de Hanzl-Wei $\beta$ (2004) discute o papel da indústria de calçados na economia de países considerados periféricos da União Europeia. E, por fim, Buxey (2005) estuda as estratégias empregadas pelas empresas australianas que souberam se adaptar às consequências adversas da globalização.

Em se tratando de estudos que focam o planejamento estratégico, tem-se: Afonso (1993) discute o padrão de concorrência e as estratégias competitivas das firmas líderes do complexo calçadista nacional; Giusti (2005) analisa o grau de competitividade das empresas brasileiras de calçados de couro em função da escolha de estratégias competitivas; já o trabalho de Bimbatti et al. (2003) faz uma análise da estratégia competitiva a ser adotada pela maior empresa calçadista da região de Franca e atribui o fortalecimento e consolidação da marca da empresa como uma estratégia de sucesso; também o trabalho de Brandão (1995) traz uma 
análise da competitividade do setor calçadista, incluindo uma segmentação da indústria calçadista e seus respectivos nichos de mercado. Referente a este assunto, o trabalho de Bimbatti e Toledo (2002) avalia a maneira pela qual as decisões de 7 empresas calçadistas de Franca, no que tange à adoção de estratégias competitivas, são influenciadas pelo seu ramo de atividades. Bimbatti (2007) tem como objetivo propor estratégia competitiva para a indústria calçadista brasileira frente ao mercado internacional. O estudo de Lima e Martins (2001) descreve a indústria de calçados de couro usando o modelo de 5 forças de Porter para estratégia competitiva e contribui, assim, para o entendimento das relações entre a indústria de calçados de couro e o seu ambiente competitivo. Orssatto (2002) traz um modelo de muita utilidade para a identificação do comportamento competitivo e do padrão estratégico desenvolvido por empresas calçadistas. Ainda referente ao planejamento estratégico, o trabalho de Orssatto (1994) chama a atenção sobre a necessidade de se ter uma correta percepção e avaliação das influências externas para que se consiga ter mudanças estratégicas efetivas. Orssatto (1995) dá continuidade ao seu trabalho anterior a partir da avaliação das similaridades dos padrões de ações estratégicas das empresas calçadistas de Novo Hamburgo-RS frente às influências político-institucionais comuns às organizações. Também os trabalhos de Francischini e Azevedo (2003a,b) mostram o impacto diferenciado do ambiente competitivo da década de 90 nas estratégias adotadas por 3 empresas calçadistas de grande porte. O trabalho de Zanini e Oliveira (2004) analisa o processo de adaptação estratégica de uma empresa calçadista do Vale dos Sinos frente às mudanças e exigências do ambiente. O trabalho de Harfield e Hamilton (1997) relata experiências advindas de donos e presidentes de empresas calçadistas da Nova Zelândia que souberam superar o declínio durante o período de crescimento da competição internacional e da liberalização econômica, podendo ser de muito valor para outros gestores e, por fim, Rhoden (2003) contribui com um modelo de administração estratégica empiricamente testado.

Focando as estratégias de produção, Fernandes e Mattiuzzo (1986) diagnosticam os problemas de uma pequena empresa da indústria calçadista, julgando que as dificuldades mais sérias se encontram relacionadas às questões do planejamento e controle da produção e do sistema produtivo. Gomes (1993) analisa os principais atores da cadeia coureiro-calçadista e a influência destes na estratégia de produção dos fabricantes de calçados de couro. Fensterseifer e Gomes (1995b) analisam o estado da indústria calçadista de couro do Vale dos Sinos em matéria de estratégia de produção e em que medida as diferentes estratégias de produção influenciam na competitividade e também identificam o papel da função produção na estratégia empresarial. Leite e Fernandes (2003b) apresentam um perfil, em termos de processo produtivo, de fatores de competitividade e de projetos de melhoria, das pequenas e médias empresas de calçados da cidade de Birigui/SP.
Já Albuquerque (1999) teve como objetivo do seu trabalho estudar a estratégia de produção e sua consistência com a estratégia competitiva. Outros estudos que focam a relação entre estratégia de produção e estratégia competitiva são os de Albuquerque e Silva (2001), Nadaleto (2003) e Fernandes e Murari (2000b), sendo que este último consegue identificar o grau de importância de cada fator estratégico produtivo para o problema da competitividade na indústria de calçados do Brasil. O trabalho de Garcia (1997) analisa as estratégias de produção de empresas calçadistas do Rio Grande do Sul. O estudo de Cavenaghi (2001) identifica o grau de alinhamento da função produção às estratégias corporativas. Por fim, Machado et al. (2005) analisam a busca da customização em massa dos produtos pelas empresas calçadistas brasileiras.

Focando a organização industrial, Debiasi (2001) traz um método de análise para identificação e mapeamento de clusters para ser aplicado nas regiões brasileiras. Já Silva e Fonseca (1995) verificam quais são os fatores que contribuem para a formação dos componentes estruturais necessários à criação de um cluster. Ruas (1995) apresenta os componentes estruturais do complexo calçadista do Rio Grande do Sul. Referente ainda a este assunto, Garcia (1996) investiga se os fatores contribuintes na formação dos componentes estruturais encontrados nos clusters internacionais podem ser verificados nos distritos industriais brasileiros. Lages (2003) discute o processo de relocalização parcial da indústria de couro-calçados do Sul e Sudeste para o Nordeste do Brasil. Alves et al. (2004) trazem um estudo comparativo entre os clusters calçadistas de Franca-SP e Campina Grande-PB. Sousa et al. (2005) analisam o processo de formação e desenvolvimento dos arranjos produtivos do Rio Grande do Sul, São Paulo e Paraíba. Lemos (2003) estuda o perfil do arranjo produtivo local de Campina Grande (PB). Crocco et al. (2003) têm por objetivo analisar a aglomeração industrial calçadista de Nova Serrana (MG). Rabellotti (1995) também traz um estudo comparativo entre clusters localizados na Itália e México. Kinloch (2002) estuda experiências bem sucedidas de clusters regionais de pequenas/médias empresas e redes de cooperação produtiva no Brasil. Schmitz (1995) mostra o papel da organização industrial como peça-chave para se alcançar a competitividade e se adaptar a ambientes desfavoráveis. Sendo assim, o estudo traz uma avaliação do sucesso do cluster calçadista do Vale dos Sinos-RS frente à estagnação e declínio da economia brasileira. Vargas e Alievi (2003) analisam o papel das aglomerações produtivas no processo de capacitação produtiva e inovativa das empresas calçadistas do Vale dos Sinos (RS). Bimbatti (2001) também avalia a maneira pela qual a performance do cluster calçadista de Franca-SP é influenciada pela adoção e prática de estratégias para maior competitividade. Motta (2001) estuda os problemas que as empresas do cluster calçadista de Franca - SP vêm enfrentando frente ao novo contexto econômico e como as relações de cooperação entre essas empresas podem 
melhorar o desempenho e aumentar a competitividade. Rabellotti (1998) analisa os efeitos econômicos coletivos advindos da ligação entre empresas de um mesmo cluster calçadista. Woodruff (1998) traz um trabalho que se mostra de grande valor para o entendimento das vantagens de se ter relações integradas entre firmas principalmente após a liberação do comércio mundial. Pereira (2001) traz um conjunto de ações a serem implementadas em nível organizacional a fim de possibilitar a adequação do setor calçadista às novas condições impostas pela evolução dos mercados. Correia (2002) estuda o crescimento em representatividade nacional do polo calçadista da região do Vale do Rio Tijucas em Santa Catarina em virtude da recente reestruturação produtiva e aglomeração industrial. Já Hansen et al. (2004) trazem uma caracterização e análise do arranjo coureiro-calçadista do Vale dos Sinos - RS e conclui que as empresas ainda continuam muito focadas em suas atividades de manufatura, atuando de maneira individual e sem o desenvolvimento de estratégias coletivas. Scott (2006) avalia a indústria de calçados sob o ponto de vista de organização industrial, localização geográfica e divisão do trabalho. Para isso, estuda os contrastes entre os países mais desenvolvidos e os menos desenvolvidos. Focando ainda a organização industrial dentro da área de estratégia e organizações, os trabalhos de Pereira e Brunstein (2002a,b; 2003) se complementam no sentido de entender o cenário das alterações mercadológicas impostas às empresas calçadistas gaúchas voltadas à exportação e identificar ações e necessidades, em termos de competências administrativas, para alavancar a performance do cluster calçadista gaúcho no cenário competitivo mundial.

Em relação ao marketing estratégico industrial, Mazocato (1989a) constata que os produtores brasileiros de calçados carecem de um posicionamento mercadológico competitivo no mercado mundial. Mazocato (1989b) complementa seu estudo anterior descrevendo que o processo exportador do calçado brasileiro é dominado pelos agentes intermediários e que estes dominam diversos estágios dos canais de distribuição. Já Carvalho (1996) traz um estudo que procura verificar se determinadas características de empresas calçadistas brasileiras estariam associadas à sua permanência ou não na atividade exportadora. Por fim, Machado Neto (2005) estuda a forma de inserção no mercado externo das fábricas de calçados de Franca - SP.

Com relação às redes de empresas, o trabalho de Rabellotti (1993) teve por objetivo entender as relações entre as empresas localizadas em dois clusters do México, compreendendo e discutindo o fenômeno da eficiência coletiva. Outros trabalhos que ressaltam os efeitos benéficos alcançados a partir da relação entre empresas são os estudos de Perry et al. (1999), Schmitz (1999), Corrêa (2000), Perez-Aleman (2000), Perry e Sohal (2001) e Garcia (2001), sendo que este último estudo traz um questionamento mais profundo sobre a real veracidade acerca das vantagens competitivas alcançadas a partir da relação entre empresas. Fensterseifer e Gomes (1995a) descrevem a cadeia produtiva do calçado de couro, permitindo que dessa maneira fatores limitantes à competitividade do setor fossem elucidados. Hsing (1999) ressalta a importância de se entender o papel das companhias comerciais dentro da cadeia produtiva de calçados, pois julga que estas são um importante fator limitante à competitividade do setor já que são centros de informação e coordenação da rede. O estudo de Vendrameto et al. (2001) também descreve a cadeia produtiva couro-calçado, ressaltando a necessidade de se aproveitar os resíduos e melhorar a condição de competitividade da cadeia produtiva. Fusco e Sacomano (2001a) trazem uma análise dos clusters de Jaú e Franca frente às mudanças no ambiente econômico, focalizando a cadeia de suprimentos e a rede de empresas. Fusco e Sacomano (2001b) objetivam a obtenção de novos argumentos e análises sobre o chamado processo de clusterização, agregando à teoria de custos de transação a ocorrência de externalidades e economias de aglomeração. Já Tristão (2002) traz uma metodologia que permite identificar sistemas industriais locais apresentando, também, uma análise da cadeia produtiva de Franca-SP. Tanto o Trabalho de Knorringar (1995) como o de Woodruff (2002) abordam uma relação não tão clara no âmbito da cadeia produtiva calçadista, que é a relação produtor-vendedor. Outra característica pouco abordada quando se fala em cadeia produtiva e que o trabalho de Suzigan et al. (2002) traz é a governança das relações interempresas da cadeia. Sendo assim, o estudo traz evidências sobre formas de coordenação e agentes coordenadores das relações entre empresas. Ainda em relação às redes de empresas, Tomelin (2000) analisa a relação formada entre empresas que se associaram em um consórcio de exportação de calçados no Estado de Santa Catarina. Bertolini et al. (2007) analisam a gestão da cadeia de suprimentos na indústria calçadista italiana, dando atenção especial à performance do lead time entre os membros da cadeia. Finalmente, Ceroni e Nof (2005) descrevem um modelo para o desenho da cadeia de suprimentos com o foco em redução de custos e no bom gerenciamento da informação de toda cadeia.

\subsubsection{Artigos referentes à gestão da tecnologia}

Focando a inovação tecnológica, Moreira (1987) analisa o nível de inovação alcançado pela indústria de calçados do Vale dos Sinos - RS quanto aos aspectos organizacionais e produtivos. Costa (1993) estuda o comportamento do setor calçadista brasileiro em relação à incorporação de inovações tecnológicas. Reis (1992) analisa as principais tendências, em nível mundial, em termos de inovações tecnológicas e organizacionais, e a difusão destas inovações na indústria brasileira de calçados. Scarso e Bolisani (1996) estudam o mecanismo de difusão da tecnologia CAD no setor calçadista italiano. Arlington e Mylius (1986) trazem um retrospecto do desenvolvimento dos sistemas CAD/ CAM na indústria do calçado e aponta os benefícios de sua utilização. Mollo Neto e Vendrametto (2003) mostram o desenvolvimento de uma "máquina de visão" a qual 
analisa eletronicamente o couro por meio de um sistema óptico digital. Silva (2005) traz um estudo com o propósito de identificar as implicações para a cadeia calçadista em virtude das transformações estruturais ocorridas nas empresas fabricantes de máquinas para a indústria calçadista. Chituc et al. (2008) analisam a utilização de ferramentas computacionais no desenvolvimento de tecnologias da informação, principalmente dentro do contexto do comércio eletrônico da indústria do calçado.

Focando os impactos e riscos tecnológicos, Rocha (1990) estuda os meios utilizados pelas micro-organizações do setor de calçados do Ceará para se manterem no mercado, visto a defasagem destas em relação à sofisticação tecnológica do mercado. Alves Filho (1991) busca em seu estudo relacionar a estratégia tecnológica da empresa com o seu desempenho e com a direção da evolução técnica da empresa; para isso, nove estudos de caso são apresentados. Henriques (2001) estuda como os conceitos de qualidade, produtividade e gerenciamento moderno têm sido aplicados nas micro e pequenas empresas calçadistas de Nova-Serrana, MG. Tanto Costa (1995) como Piccinini (1995b) abordam os efeitos da introdução do progresso técnico sobre o emprego e também sobre as relações de trabalho. Por fim, Zawislak (1995) caracteriza a atividade de inovação tecnológica advinda a partir do conhecimento empírico dos recursos humanos ligados ao chão de fábrica e suas consequências para a empresa.

Com relação às redes de empresas, Souza e Fernandes (2001) analisam os efeitos causados pela influência das relações interfirmas sobre os principais fatores tecnológicos e gerenciais que envolvem tal contexto .

\subsubsection{Artigos referentes aos sistemas de informação}

Com relação aos sistemas de informações gerenciais, tanto Bimbatti e Laurindo (2002) como Silva (2002a) trazem um estudo da situação atual da utilização dos sistemas MRP, MRP II e ERP no gerenciamento da produção por parte de empresas calçadistas de Franca-SP. Silva e Fernandes $(2003 ; 2004)$ retratam, em ambos os trabalhos, os principais aspectos que devem ser considerados a respeito do uso dos sistemas ERP assim como o relacionamento entre estes aspectos.

Com o foco em planejamento de sistemas de informação, Koppel (1992) identifica um processo de mudança do sistema de informação de uma empresa vendedora de calçados que objetiva providenciar análises gerenciais e suporte para decisões da empresa.

Focando os sistemas de apoio à decisão, Castro et al. (2004) abordam em seu estudo o uso da ferramenta OLAP (On Line Analytical Processing) na estratégia de vendas em uma empresa do setor calçadista.

Dentro da subárea administração estratégica da informação, Silva (1999) mostra que a maneira pela qual as empresas calçadistas de Campina Grande-PB gerenciam suas informações está diretamente relacionada à obtenção de vantagens competitivas. Por fim, Holanda et al. (2005) procuram identificar os tipos de práticas gerenciais e seus relacionamentos com a criação, disseminação e compartilhamento do conhecimento dentro da fábrica.

\subsubsection{Artigos referentes à gestão ambiental}

Dois artigos abordam essa área, ambos com o foco em gestão de resíduos. Viegas (1997) mostra o vínculo entra capacidade tecnológica e gestão ambiental, propondo um modelo de gestão de resíduos sólidos para a indústria calçadista. Já Vasconcelos e Ferreira (2004) relatam alguns dos resultados da implementação, por parte de uma empresa calçadista, de um programa de responsabilidade sócio-ambiental a partir da gestão de resíduos do seu processo produtivo.

\subsection{Trabalhos que focam mais de uma grande área da engenharia de produção}

Quatro trabalhos focam as áreas de Gerência de Produção e Estratégia e Organizações. Salomão e Alves Filho (1998) e Salomão (1998) analisam as estratégias de produção e as estratégias de gestão de pessoal implementadas por duas empresas calçadistas. Francischini e Azevedo (2002) analisam o processo de mudança técnica de uma empresa do setor de calçados frente ao novo ambiente institucional marcado pelo aumento da competição entre os países. Por fim, Godinho Filho (2004) traz uma análise dos principais Paradigmas Estratégicos de Gestão da Manufatura, relacionando-os a objetivos estratégicos da manufatura, bem como a importantes aspectos do controle da produção.

Oito trabalhos focam as áreas de Gerência de Produção e Gestão da Tecnologia. Cunha (2003) avalia a potencialidade técnica e a Gestão da Produção de três grandes empresas calçadistas. O estudo relata que o processo de fabricação de calçados ainda está longe de um sistema de manufatura avançada com sistemas automatizados. Savegnani e Sacomano (2003a,b) baseiam-se na estratégia de manufatura e tecnologia de equipamentos para demonstrar a importância das máquinas e equipamentos no processo produtivo do couro e do calçado. Sousa et al. (2004) exploram o processo de gestão da inovação tecnológica levantando as vantagens e desvantagens do sistema de produção puxado em substituição ao sistema de produção empurrado. Motta e Escrivão Filho (2003) discutem a especialização flexível e o surgimento dos clusters como forma de explorar competências de várias pequenas empresas. Piccinini (1995a) preocupa-se em conhecer o nível de desenvolvimento tecnológico das empresas brasileiras de calçados, a organização da produção e em que medida os trabalhadores estão sendo preparados para as mudanças de caráter tecnológico. Já Piccinini (1994) contribui na discussão sobre novas tecnologias automatizadas e sua repercussão na qualificação da mão de obra do setor. 
Blos (2003) avalia o impacto da implantação de células de trabalho em alguns importantes fatores que posicionam a empresa calçadista no ambiente competitivo.

Dois trabalhos têm o foco em Gerência de Produção e Ergonomia e Segurança do Trabalho. Kmita et al. (2003) estuda os fatores físico-ambientais de uma empresa fabricante de palmilhas para calçados, propondo melhorias ergonômicas para a execução do trabalho com mudanças em layout, ventilação e iluminação fabril. Silva (2001) visa melhorar a organização do trabalho em uma empresa calçadista a partir do redesenho do layout da fábrica.

Um único trabalho que foca as áreas de Gerência de Produção e Pesquisa Operacional faz parte deste grupo. Murari (1997) contribui com um estudo que visa tanto aprimorar o PCP das empresas de calçados como também servir para o avanço dos estudos ligados ao problema de corte e empacotamento bidimensional para peças com formato irregular.

Dois trabalhos focam as áreas Gerência de Produção e Sistemas de Informação. Souza (2002) e Silva (2002b) referem-se ao desenvolvimento de um sistema de planejamento e controle da produção capaz de coordenar os membros do cluster de Birigui - SP.

Um trabalho tem o foco nas áreas de Qualidade e Ergonomia e Segurança do Trabalho. Antunes (1995) indaga sobre a atitude gerencial em relação à participação dos empregados em face da implantação de inovações organizacionais que conduzem à Gestão da Qualidade.

Um único artigo foca as áreas de Qualidade e Estratégia e Organizações. Severo et al. (2004) estudam a importância estratégica do sistema de gestão da qualidade para aumentar a competitividade das empresas do setor de calçados esportivos.

Um trabalho foca as áreas de Qualidade e Gestão Tecnológica. Abrunhosa e Sá (2008) analisam o impacto do TQM (Total Quality Management) na inovação tecnológica da indústria de calçados de Portugal.

Somente um trabalho foca as áreas de Ergonomia e Segurança do Trabalho e Gestão da Tecnologia. Ruas (1987) traz uma pesquisa acerca das transformações da indústria de calçados do Rio Grande do Sul resultantes da introdução de tecnologias mais modernas e dos impactos destas mudanças sobre a organização do trabalho.

Um único artigo foca a área de Engenharia do Produto e Gestão da Tecnologia. Cardoso (1993) traz em seu estudo informações sistematizadas em torno do produto calçado, objetivando fornecer subsídios para avaliação e projeto de calçados. Além disso, apresenta uma visão panorâmica do atual estágio tecnológico do setor calçadista mundial com $\mathrm{o}$ intuito de nortear a adoção de estratégias tecnológicas para o setor no Brasil que possibilitem um incremento na qualidade do produto.

Somente um trabalho foca a área de Estratégia e Organizações e Gestão Ambiental. Ruppenthal (2001) trata sobre a questão das relações entre o meio ambiente e a competitividade face à globalização dos mercados e à introdução da variável ambiental em um importante setor da economia brasileira que é o setor couro.

Apenas um único artigo foca as áreas de Gestão da Tecnologia e Sistemas de Informação. Arce et al. (2001) pesquisam as condições para a implantação de um sistema integrado de processamento das informações dos pedidos recebidos dos clientes e fabricação dos calçados de forma personalizada por meio de um sistema de Manufatura Integrada por Computador (CIM).

\section{Análise da pesquisa existente em Gestão da Produção na indústria de calçados e sugestões de futuros estudos (Passo 5 da pesquisa)}

Esta seção traz uma análise geral da revisão bibliográfica utilizando-se o sistema de classificação proposto. Esta análise se baseia em dois pontos essenciais: i) estudo quantitativo da distribuição dos trabalhos entre as grandes áreas, origens, metodologias e fontes assim como ii) estudo qualitativo dos principais assuntos e objetivos alcançados por esses trabalhos.

\subsection{Análise quantitativa das grandes áreas, origens, metodologias e fontes}

Esta análise se baseia na classificação de trabalhos propostos e tem por objetivo verificar qual a distribuição dos trabalhos entre as grandes áreas, origens, metodologias e fontes dentro da literatura referente à Gestão da Produção na indústria calçadista.

A primeira constatação a respeito dos trabalhos é a desproporção da distribuição destes entre as grandes áreas da Engenharia de Produção. A Figura 1 evidencia tal fato.

Sendo assim, temos que 30,14\% (63) dos artigos focam a Gerência de Produção e 41,15\% (86) focam a área Estratégia e Organizações. Estas se enquadram, portanto, como as áreas mais estudadas em Engenharia de Produção na indústria calçadista. As menos estudadas dentro do tema são Gestão Ambiental (1,44\% do total) e Ensino de Engenharia de Produção com nenhum trabalho. Uma observação importante a respeito das porcentagens é que elas não somam 100\% (caso se somasse a porcentagem de trabalhos que focam cada grande área), pois há trabalhos que foram classificados em mais de uma área.

Com relação à comparação entre a produção científica internacional frente à nacional tem-se que 170 trabalhos são nacionais e apenas 39 internacionais

A distribuição dos trabalhos entre as diversas fontes resultou no seguinte comparativo: 66 trabalhos englobam publicações realizadas nas fontes ENEGEP, SIMPOI e SIMPEP (37 no ENEGEP, 7 no SIMPOI e 22 no SIMPEP); 49 trabalhos são dissertações; 16 são teses; 12 trabalhos foram publicados em livros; 61 em revista científica, sendo 40 em periódico científico qualificado (Internacional A ou B, ou Nacional A segundo o Qualis) e 21 em revista 
técnico-científica; e 5 trabalhos englobaram outras fontes que não as mencionadas. Constata-se que a maior incidência de publicação de trabalhos relacionados ao tema se dá em revistas científicas, 29,19\% do total; chamando a atenção também o elevado número de trabalhos de dissertação sobre o tema (23,44\% do total).

Em se tratando de metodologia de pesquisa tem-se que: 171 trabalhos são estudos de caso; 29 são pesquisa de avaliação ou survey; 5 são pesquisa-ação; 3 são teóricoconceitual; e apenas 1 trabalho é revisão bibliográfica. Observa-se o predomínio do estudo de caso como procedimento de pesquisa adotado pelos autores dos trabalhos, o que representa $81,82 \%$ do total.

\subsection{Análise qualitativa e sugestão de futuras pesquisas}

Esta análise baseia-se na revisão bibliográfica estruturada apresentada na seção 4 e tem por principal objetivo servir de subsídio para maior entendimento da literatura existente sobre Gestão da Produção na indústria calçadista, assim como sugerir novas pesquisas na área. Os pontos mais importantes a serem destacados são:

- Alguns autores realizam estudos de caso para apresentar um comparativo entre o sistema de produção, em reestruturação, utilizado pela empresa em questão, que é Taylorista-Fordista de produção em massa, e o sistema de produção enxuto. Exemplos destes trabalhos são Tubino e Lopes (1996), Albuquerque et al. (1999), Diedrich (2002), Rentes et al. (2003). Parece que há a emergência de uma nova realidade na produção industrial calçadista brasileira no tocante à implantação da mentalidade enxuta nas empresas. Outros estudos poderiam quantificar e justificar a implantação de técnicas enxutas nas empresas calçadistas, trazendo experiências sobre a transição e reestruturação do sistema produtivo.

Observam-se nos estudos, por parte de alguns autores, algumas preocupações a respeito do comportamento do setor calçadista nacional frente à abertura comercial dos anos 90 . Estudos como os de Costa (1993), Leite e Fernandes (2003), e Francischini e Azevedo (2002) demonstram o dinamismo das empresas calçadistas na incorporação de novas tecnologias de maneira a melhorarem a competitividade. Os trabalhos de Kochan (1996) e Rooks (1996) trazem experiências de empresas internacionais que obtiveram benefícios sólidos após a incorporação de mudanças técnicas principalmente relacionadas à automação industrial. Este tema, relacionado à modernização das empresas calçadistas brasileiras, está longe de estar esgotado.

Dentro desta seção de análise baseada na seção anterior, há uma constatação bastante interessante. Há pouquíssimos trabalhos que abordam o processo de desenvolvimento do produto calçado. Os únicos foram os de Santos (1998), Pinotti (2003) e Cezar et al. (2003). Visto que o calçado é um produto ligado às tendências de moda, e por isso dependente dos gostos e subjetividades dos usuários, assim como é ele o diferencial entre as empresas, essa questão pode ser melhor estudada no futuro.

Vários autores focalizam os clusters calçadistas dentro de contextos específicos em que se encontram inseridos (RABELLOTTI (1995), SCHMITZ (1995), SCHMITZ (1999), MOTTA e ESCRIVÃO FILHO (2003)). Parece haver um consenso, por parte dos autores, em relação ao papel que a organização industrial, representada pela formação de um cluster, exerce sobre a competitividade das empresas. Para Rabellotti (1995), a organização de empresas em clusters aumenta a capacidade de reação a mudanças radicais. Há amplo espaço na literatura para estudos que comparem clusters calçadistas em diferentes países ou em diferentes regiões do País, principalmente tentando concluir sobre quais são, de fato, as condições externas em que as cooperações locais de um cluster têm maior eficácia.

\section{Conclusões}

A indústria brasileira de calçados é um importante setor da economia do País por seu volume de produção, por sua

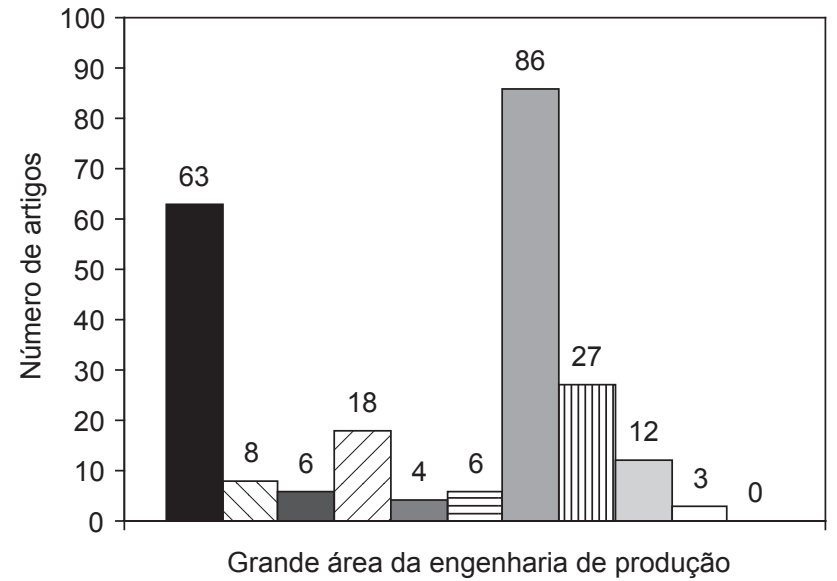

$$
\begin{aligned}
& \square \text { Gerencia de Produção } \\
& \forall \text { Qualidade } \\
& \square \text { Gestao Economica } \\
& \square \text { Ergonomia e Seguranca do Trabalho } \\
& \square \text { Engenharia do Produto } \\
& \boxminus \text { Pesquisa Operacional } \\
& \square \text { Estrategia e Organizações } \\
& \square \text { Gestão da Tecnologia } \\
& \square \text { Sistemas de Informação } \\
& \square \text { Gestão Ambiental } \\
& \square \text { Ensino de Engenharia de Produção }
\end{aligned}
$$

Figura 1. Número de artigos de acordo com a área da Engenharia de Produção focada. 
expressiva participação na pauta de exportações e pela sua capacidade de geração de empregos. Certamente é um setor que merece relevante atenção.

A Engenharia de Produção é uma área interdisciplinar e as fontes de informação para a pesquisa em Engenharia de Produção podem vir de outras áreas do conhecimento como da Economia e das Ciências da Organização (que envolvem temas ligados à Administração, à Sociologia, às Ciências Ambientais, à Psicologia e à Matemática Aplicada). Portanto, a partir da ampla revisão bibliográfica sobre Gestão da Produção na indústria calçadista pode-se dizer, em primeiro lugar, que o presente trabalho serviu para compilar e relacionar o conhecimento sobre esta importante indústria brasileira.

A partir da revisão da literatura pôde-se propor um sistema de classificação e codificação de trabalhos com base em cinco dimensões: origem, grande área da Engenharia de Produção, subárea da Engenharia de Produção, procedimento de pesquisa e fonte do trabalho. Utilizando esse sistema foram classificados todos os artigos encontrados na literatura. Esse procedimento serviu de base para a estruturação de toda a revisão bibliográfica e para uma ampla análise (quanti e qualitativa) do tema. As principais contribuições deste trabalho são: i) maior conhecimento do tema; ii) ser útil para pesquisadores que desenvolvem estudos na indústria de calçados; iii) servir para empresários e gerentes que trabalham na indústria de calçados, de maneira a identificar fontes de resolução de problemas; iv) direcionar estudos semelhantes a respeito da Engenharia de Produção em outras indústrias; e v) sugerir futuras pesquisas dentro do tema.

\title{
Research on Production Management in the footwear industry: review, classification, and analysis
}

\begin{abstract}
This paper presents a literature review that intends to be complete including 209 papers on Production Management on footwear industry since 1980. Such a review has not yet been available on the Production Management literature. This review was organized by means of a classification encompassing 5 dimensions: paper origin, area of Production Engineering focused in the paper, sub area of Production Engineering focused, research procedure used, and the paper source. Once classified and organized, the literature review about Production Management on footwear industry was the base of a broad theme analysis. This analysis was based on two basic points: i) a quantitative study on the areas of Production Engineering focused in the papers such as the origin, source, and research procedure used and ii) a qualitative study on the main subjects and objectives discussed and met in those papers. The main contributions of this paper are being useful to increase the amount of literature available on Production Management in the footwear industry and suggestions for future researches.
\end{abstract}

Key words: Footwear industry. Production management. Literature revision.

\section{Referências Bibliográficas}

ABICALÇADOS. Resenha estatística 2008. Disponível em: <http:// www.abicalcados.com. br>. Acesso em: 13 de Novembro de 2008.

ABRUNHOSA, A.; SÁ, P. M. Are TQM principles supporting innovation in the portuguese footwear industry? Technovation, v. 28, n. 4, p. 208-221, 2008.

AFONSO, C. A. M. Padrão de concorrência e estratégia competitiva: um estudo do complexo têxtil/calçados. 1993. 150 p. Dissertação (Mestrado em Economia da Indústria e da Tecnologia) - Universidade Federal do Rio de Janeiro, Rio de Janeiro.

ALBUQUERQUE, E. E. M. Estratégia de manufatura em uma planta industrial de calçados: um estudo da sua consistência com a estratégia competitiva. 1999. 126 p. Dissertação (Mestrado em Engenharia de Produção) - Universidade Federal da Paraíba, João Pessoa.
ALBUQUERQUE, E. E. M.; ARAÚJO, G. S. M.; SEVERIANO FILHO, C. A lógica do sistema Kanban na indústria calçadista: análise de um sistema de programação da produção de solados e palmilhas. In: ENCONTRO NACIONAL DE ENGENHARIA DE PRODUÇÃO - ENEGEP, 19., 1999, Rio de Janeiro. Anais... Rio de Janeiro: UFRJ; ABEPRO. 1 CD-ROM.

ALBUQUERQUE, M. E. E.; SILVA, F. A. C. A estratégia de produção de uma empresa de calçados e sua consistência com a estratégia competitiva. Revista Tecnicouro, v. 22, n. 3, p. 30-42, 2001

ALVES FILHO, G. A. Estratégia tecnológica, desempenho e mudança: estudos de caso em empresas da indústria de calçados. 1991. 189 p. Tese (Doutorado em Engenharia de Produção) - Escola Politécnica, Universidade de São Paulo, São Paulo.

ALVES, E. A.; BRAGA FILHO, H. Reestruturação produtiva na indústria calçadista francana: expressões da precarização do ambiente fabril. In: SIMPÓSIO NACIONAL DE ENGENHARIA DE PRODUÇÃO - SIMPEP, 12., 2005, Bauru. Anais... Bauru: 
Editora da Unesp, 2005. Disponível em: <www.simpep.feb.unesp. br>. Acesso em: 16 de Julho de 2006.

ALVES, S. J.; SOUSA, V. R. T.; MOUTINHO, G. M. L.; CAVALCANTI FILHO, B. M. F. P. Arranjos produtivos e inovativos locais de calçados: um estudo comparativo dos APILs de Franca/ SP e Campina Grande/PB. In: SIMPÓSIO NACIONAL DE ENGENHARIA DE PRODUÇÃO - SIMPEP, 11., 2004, Bauru. Anais... Bauru: Editora da Unesp, 2004. Disponível em: <www. simpep.feb.unesp.br>. Acesso em: 16 de Julho de 2006.

ANTUNES, D. D. E. Atitudes gerenciais quanto à participação dos trabalhadores na gestão da qualidade. In: FENSTERSEIFER, J. E. (Org.). O complexo calçadista em perspectiva: tecnologia e competitividade. Porto Alegre: Ortiz, 1995.

ANZANELLO, J. M.; FOGLIATTO, S. F. Procedimento para direcionamento de itens produzidos em pequenos lotes a equipes de trabalhadores em linhas de produção. In: ENCONTRO NACIONAL DE ENGENHARIA DE PRODUÇÃO - ENEGEP, 24., 2004, Florianópolis. Anais... Florianópolis: UFSC; ABEPRO, 2004. 1 CD-ROM.

ANZANELLO, M. J.; FOGLIATTO, F. S. Alocação de modelos de produtos a equipes de trabalhadores baseada em modelos de curvas de aprendizagem. Revista Produção, v. 15, n. 2, p. 221-234, 2005.

ARCE, S. J.; VENDRAMETO, O.; BARRELLA, D. W. O futuro da fábrica de calçados. In: ENCONTRO NACIONAL DE ENGENHARIA DE PRODUÇÃO - ENEGEP, 21., 2001, Salvador. Anais... Salvador: FTC; ABEPRO, 2001. 1 CD-ROM.

ARLINGTON, M.; MYLIUS, M. S. Usos e benefícios do CAD/ CAM na indústria do calçado. Revista Tecnicouro, v. 8, n. 2, p. 38-40, 1986.

AZEVEDO, P. A. Papel dos sistemas de custos do processo de decisão das pequenas e médias indústrias coureiro-calçadista do estado da Paraíba. 1997. 141 p. Dissertação (Mestrado em Administração) - Universidade Federal da Paraíba, João Pessoa.

BAMFORD, D. R.; LAND, N. The application and use of the PAF quality costing model within a footwear company. International Journal of Quality \& Reability Management, v. 23, n. 3, p. 265-278, 2006.

BARNETT, L.; RAHIMIFARD, S.; NEWMAN, S. Distributed scheduling to support mass customization in the shoe industry. International Journal of Computer Integrated Manufacturing, v. 17, n. 7, p. 623-632, 2004.

BENINI FILHO, A. P.; MARTINS, S. S.; MARÇULA, M. Um estudo do planejamento, programação e controle da produção no cluster calçadista de Birigui. In: SIMPÓSIO NACIONAL DE ENGENHARIA DE PRODUÇÃO - SIMPEP, 8., 2001, Bauru. Anais... Bauru: Editora da Unesp, 2001. Disponível em: <www. simpep.feb.unesp.br>. Acesso em: 16 de Julho de 2006.

BENITES, T. O. Delineamento de um sistema de custos com base na abordagem $\mathrm{ABC}$ para a pequena fabricação de calçados. 1996. 179 p. Dissertação (Mestrado em Engenharia de Produção) - Universidade Federal da Paraíba, João Pessoa.

BERTOLINI, M.; BOTTANI, E.; RIZZI, A.; BEVILACQUA, M. Lead Time reduction through ICT application in the footwear industry: a case study. International Journal of Production Economics, v. 110, n. 1, p. 198-212, 2007.

BERTO, R. M. V. S.; NAKANO, D. N. Metodologia da pesquisa e a Engenharia de Produção. In: ENCONTRO NACIONAL DE ENGENHARIA DE PRODUÇÃO - ENEGEP, 18., 1998, Niterói. Anais... Niterói: UFF; ABEPRO, 1998. 1 CD-ROM.

BERTO, R. M. V. S.; NAKANO, D. N. A produção científica nos anais do encontro nacional de engenharia de produção: um levantamento dos métodos e tipos de pesquisa. In: ENCONTRO NACIONAL DE ENGENHARIA DE PRODUÇÃO - ENEGEP, 19., 1999, Rio de Janeiro. Anais... Rio de Janeiro: UFRJ; ABEPRO, 1999.
1 CD-ROM. (Trabalho apresentado também no $5^{\circ}$ International Congress of Industrial Engineering).

BERTO, R. M. V. S.; NAKANO, D. N. A produção científica nos anais do encontro nacional de Engenharia de Produção: um levantamento dos métodos e tipos de pesquisa. Produção, v. 9, n. 2, p. 65-75, 2000.

BIEHL, A. K.; MOSELE, E. Análise da percepção do operário calçadista frente às formas tradicional, celular, e grupos de trabalho de organização da produção. In: ENCONTRO NACIONAL DE ENGENHARIA DE PRODUÇÃO - ENEGEP, 23., 2003, Ouro Preto. Anais.... Ouro Preto: UFOP; ABEPRO, 2003. 1 CD-ROM.

BIMBATTI, M. Indústria calçadista de Franca/SP: panorama atual e sugestões de estratégias para maior competitividade. In: SIMPÓSIO NACIONAL DE ENGENHARIA DE PRODUÇÃO - SIMPEP, 8., 2001, Bauru. Anais... Bauru: Editora Unesp, 2001. Disponível em: <www.simpep.feb.unesp.br>. Acesso em: 16 de Julho de 2006.

BIMBATTI, M. L. Como enfrenta o fenômeno China na produção de calçados: proposta de estratégia competitiva para a indústria calçadista brasileira. 2007. 190 p. Tese (Doutorado em Engenharia de Produção) - Escola Politécnica, Universidade de São Paulo, São Paulo.

BIMBATTI, M.; LAURINDO, B. J. F. TI na indústria calçadista de Franca, panorama atual - futuro promissor. In: SIMPÓSIO NACIONAL DE ENGENHARIA DE PRODUÇÃO - SIMPEP, 9., 2002, Bauru. Anais... Bauru: UNESP, 2002. Disponível em: <www. simpep.feb.unesp.br>. Acesso em: 16 de Julho de 2006.

BIMBATTI, M.; LAURINDO, F. J. B.; TOLEDO, N. N. Operação estratégica conjunta MRP / JIT na indústria calçadista. In: SIMPÓSIO NACIONAL DE ENGENHARIA DE PRODUÇÃO SIMPEP, 12., 2005, Bauru. Anais... Bauru: Editora da Unesp, 2005. Disponível em: <www.simpep.feb.unesp.br>. Acesso em: 16 de Julho de 2006.

BIMBATTI, M.; TOLEDO, N. N. Indústria calçadista de Franca: estratégia para o sucesso competitivo. In: SIMPÓSIO DE ADMINISTRAÇÃO DA PRODUÇÃ̃O, LOGÍSTICA E OPERAÇÕES INTERNACIONAIS, 2002, São Paulo. Anais... São Paulo: FGV-EAESP, 2002. 1 CD-ROM.

BIMBATTI, M.; TOLEDO, N. N.; SHIMIZU, T. Marca, diferenciação estratégica da indústria calçadista. In: SIMPÓSIO NACIONAL DE ENGENHARIA DE PRODUÇÃO - SIMPEP, 10., 2003, Bauru. Anais... Bauru: Editora da UNESP, 2003. Disponível em: <www. simpep.feb.unesp.br>. Acesso em: 16 de Julho de 2006.

BLOS, E. Um comparativo de implantação de células de trabalho na produção da indústria calçadista: o caso da calçados Beira Rio S.A. 2003. 148 p. Dissertação (Mestrado em Administração) Universidade Federal do Rio Grande do Sul, Porto Alegre.

BOF, L.; SELLITTO, A. M.; BORCHARDT, M. Medição de tempos de atravessamento e inventário em sistemas produtivos baseados em ordens de fabricação. In: ENCONTRO NACIONAL DE ENGENHARIA DE PRODUÇÃO - ENEGEP, 23., 2003, Ouro Preto. Anais... Ouro Preto: UFOP; ABEPRO, 2003. 1 CD-ROM.

BOSCOLO, P. F. E. LER/DORT e ações ergonômicas nas empresas: estudo de casos na indústria calçadista. São Carlos, 2002. Dissertação (Mestrado em Engenharia de Produção) - Universidade Federal de São Carlos, São Carlos.

BRANDÃO, F. Grupos estratégicos e inovação tecnológica no complexo calçadista do Rio Grande do Sul. In: FENSTERSEIFER, J. E. (Org.). O complexo calçadista em perspectiva: tecnologia e competitividade. Porto Alegre: Ortiz, 1995.

BRENNER, G. A indústria de calçados no Brasil: trabalho, competição e produtividade. 1990. 210 p. Dissertação (Mestrado em Economia) - Universidade Federal do Rio Grande do Sul, Porto Alegre.

BRYMAN, A. Research methods and organization studies. London: Uniwin Hyman, 1989. 
BUXEY, G. Globalisation and manufacturing strategy in the TCF industry. International Journal of Operations \& Production Management, v. 25, n. 2, p. 100-113, 2005.

CARDOSO, A. C. O produto calçado e seu sistema produtivo. 1993. 173 p. Dissertação (Mestrado em Engenharia de Produção) Universidade Federal do Rio de Janeiro, Rio de Janeiro.

CARVALHO, M. Barreiras à exportação: sua influência na continuidade da atividade exportadora na indústria brasileira de calçados. 1996. 108 p. Dissertação (Mestrado em Administração) Universidade Federal do Rio de Janeiro, Rio de Janeiro.

CARVALHO, R. C. F. M. A microempresa de calçados de Campina Grande e o gerenciamento de sua mão-de-obra: estudo de caso. 1998. 118 p. Dissertação (Mestrado em Engenharia de Produção) - Universidade Federal da Paraíba, João Pessoa.

CARVALHO, R. C. F. M. O gerenciamento da mão-de-obra na microempresa de calçados de Campina Grande-PB. In: ENCONTRO NACIONAL DE ENGENHARIA DE PRODUÇÃO (ENEGEP), 18., 1998, Niterói. Anais... Niterói: UFF; ABEPRO, 1998. 1 CD-ROM.

CASTRO, A. S.; GONÇALVES, R. P.; CAZARINI, W. E. O uso do OLAP na estratégia de vendas em uma indústria de calçados alavancando a gestão de cadeia de suprimentos. In: ENCONTRO NACIONAL DE ENGENHARIA DE PRODUÇÃO - ENEGEP, 24., 2004, Florianópolis. Anais... Florianópolis: UFSC; ABEPRO, 2004. 1 CD-ROM.

CAVENAGHI, V. Gestão do desempenho empresarial: a contribuição da área de manufatura. 2001. 227 p. Tese (Doutorado em Engenharia de Produção) - Escola Politécnica, Universidade de São Paulo, São Paulo.

CERONI, J. A.; NOF, S. Y. Task parallelism in distributed supply organizations: a case study in the shoe industry. Production Planning \& Control, v. 16, n. 5, p. 500-513, 2005.

CEZAR, R. M.; MORO, P. R. A.; JORGE, P. M. I.; REIS, F. P. O conforto em calçados: atualidades. In: ENCONTRO NACIONAL DE ENGENHARIA DE PRODUÇÃO - ENEGEP, 23., 2003, Ouro Preto. Anais... Ouro Preto: UFOP; ABEPRO, 2003. 1 CD-ROM.

CHITUC, C. M.; TOSCANO, C.; AZEVEDO, A. Interoperability in collaborative networks: independent and industry-specific initiatives - The case of the footwear industry. Computers in Industry, v. 59, n. 7, p. 741-757, 2008.

CIAPPEI, C.; SIMONI, C. Drivers of new product sucess in the Italian sport shoe cluster of Montebelluna. Journal of Fashion Marketing and Management, v. 9, n. 1, p. 20-42, 2005.

CIOSAKI, M. L. Gerenciamento visual da produção e trabalho em grupos: ferramentas do sistema just in time aplicados simultaneamente em uma indústria de calçados. 1999. 135 p. Dissertação (Mestrado em Engenharia de Produção) - Escola de Engenharia de São Carlos, Universidade de São Paulo, São Carlos.

CIOSAKI, M. L.; COLENCI Jr., A. Gerenciamento visual da produção, implantação de células de fabricação e alterações na forma de remunerar a força de trabalho aplicados simultaneamente em uma indústria de calçados. In: ENCONTRO NACIONAL DE ENGENHARIA DE PRODUÇÃO - ENEGEP, 18., 1998, Niterói. Anais... Niterói: UFF; ABEPRO, 1998. 1 CD-ROM.

CORREAA, P. A. O arranjo produtivo coureiro-calçadista de Campina Grande, Paraíba, Brasil. 2000. 173 p. Dissertação (Mestrado em Economia) - Universidade Federal do Rio de Janeiro, Rio de Janeiro.

CORREIA, C. P. A indústria de calçados no Vale do Rio Tijucas (SC): uma abordagem à luz do debate sobre aglomerações produtivas especializadas. 2002. 122 p. Dissertação (Mestrado em Economia) Universidade Federal de Santa Catarina, Florianópolis.

COSTA, B. A. Modernização e competitividade da indústria de calçados brasileira. 1993. 275 p. Tese (Doutorado em Economia da Indústria e da Tecnologia) - Universidade Federal do Rio de Janeiro, Rio de Janeiro.

COSTA, M. B. Os impactos do progresso técnico sobre o emprego, a qualificação e as relações de trabalho: um estudo de caso na indústria de calçados do Rio Grande do Sul. 1995. 186 p. Dissertação (Mestrado em Sociologia) - Universidade Federal do Rio Grande do Sul, Porto Alegre.

CRESWELL, J. W. Research design: qualitative \& quantitative approaches. London: Sage, 1994.

CROCCO, M.; SANTOS, F.; SIMÕES R.; HORÁCIO, F. Industrialização descentralizada: sistemas industriais locais. O arranjo produtivo calçadista de Nova Serrana (MG). Revista Parcerias Estratégicas, v. 15, n. 17, p. 54-134, 2003.

CRUZ, R. A qualificação da força de trabalho na adoção de novas técnicas de organização do trabalho: estudo de caso na indústria calçadista do Vale do Rio dos Sinos. In: FENSTERSEIFER, J. E. (Org.). O complexo calçadista em perspectiva: tecnologia e competitividade. Porto Alegre: Ortiz, 1995. p. 22-35.

CUNHA, C. A. C. Avaliação do perfil tecnológico do pólo calçadista da Paraíba. In: ENCONTRO NACIONAL DE ENGENHARIA DE PRODUÇÃO - ENEGEP, 23., 2003, Ouro Preto. Anais... Ouro Preto: UFOP; ABEPRO, 2003. 1 CD-ROM.

CUNHA, C. A. C.; SEVERIANO FILHO, C.; WANDERLEY, C. M. J. Produtividade de manufatura celular puxada versus linear empurrada: estudo de caso em uma fábrica de calçados esportivos. In: ENCONTRO NACIONAL DE ENGENHARIA DE PRODUÇÃO ENEGEP, 22., 2002, Curitiba. Anais... Curitiba: PUC-PR; ABEPRO, 2002. 1 CD-ROM.

CUNHA, C. A. C.; WANDERLEY, C. M. J.; SEVERIANO FILHO, C. Estudo comparativo da produtividade entre os sistemas de produção puxada e empurrada da indústria de calçados: o caso Cambuci. In: ENCONTRO NACIONAL DE ENGENHARIA DE PRODUÇÃO - ENEGEP, 23., 2003, Ouro Preto. Anais... Ouro Preto: UFOP; ABEPRO, 2003. 1 CD-ROM.

DEBIASI, F. Modelo de identificação e mapeamento de clusters para elaboração de propostas de desenvolvimento regional. 2001. 162 p. Dissertação (Mestrado em Engenharia de Produção) Universidade Federal de Santa Catarina, Florianópolis.

DIAS, V. L. S. Proposta de uma sistemática de planejamento e controle da produção do chão de fábrica no curtíssimo prazo a partir do Índice de Eficiência Global, o IEG. In: ENCONTRO NACIONAL DE ENGENHARIA DE PRODUÇÃO - ENEGEP, 24., 2004, Florianópolis. Anais... Florianópolis: UFSC; ABEPRO, 2004. 1 CD-ROM.

DIEDRICH, H. Utilização de conceitos do Sistema Toyota de Produção na melhoria de um processo de fabricação de calçados. 2002. 98 p. Dissertação (Mestrado Profissionalizante em Engenharia) - Escola de Engenharia, Universidade Federal do Rio Grande do Sul, Porto Alegre.

DULIO, S.; BOËR, C. Integrated production plant (IPP): na innovative laboratory for research projects in the footwear field. International Journal of Computer Integrated Manufacturing, v. 17, n. 7, p. 601-611, 2004

EIDELWEIN, R. P.; SCHNORRENBERGER, A.; SANTOS, S. H. C. Análise do valor: estudo de caso em uma indústria de calçados. In: ENCONTRO NACIONAL DE ENGENHARIA DE PRODUÇÃO - ENEGEP, 23., 2003, Ouro Preto. Anais... Ouro Preto: UFOP; ABEPRO, 2003. 1 CD-ROM.

ESTIVALET, S. P.; SILVA, A. E.; LINDEN, S. C. J.; PAULA, S.; BORELLI, G. F.; FONTOURA, C. Avaliação ergonômica de máquina de costura. In: In: ENCONTRO NACIONAL DE ENGENHARIA DE PRODUÇÃO - ENEGEP, 24., 2004, Ouro Preto. Anais... Ouro Preto: UFOP; ABEPRO, 2004. 1 CD-ROM.

ESTRELA, G. Q. Tipologia das perdas dos sistemas produtivos. Revista Tecnicouro, v. 22, n. 2, p. 6, 2001. 
ESTRELA, Q. G.; SEVERIANO FILHO, C.; FELINTO, R. A. Formação do preço de venda na indústria de calçados: um estudo multicaso. In: ENCONTRO NACIONAL DE ENGENHARIA DE PRODUÇÃO - ENEGEP, 22., 2002, Ouro Preto. Anais... Ouro Preto: UFOP; ABEPRO, 2002. 1 CD-ROM.

FANTI, P. M.; MAIONE, B.; PISCITELLI, G.; TURCHIANO, B. Heuristic scheduling of jobs on a multi-product batch processing machine. International Journal of Production Research, v. 34, n. 8, p. 2163-2186, 1996.

FARIA, S. M. Se a coisa é por aí, que Autogestão é essa?: um estudo da experência autogestionária dos trabalhadores da Markeli calçados. 1997. 143 p. Dissertação (Mestrado em Administração) Universidade Federal de Santa Catarina, Florianópolis.

FENSTERSEIFER, E. J.; GOMES, A. J. Análise da cadeia produtiva do calçado do couro. In: FENSTERSEIFER, J. E. (Org.). O complexo calçadista em perspectiva: tecnologia e competitividade. Porto Alegre: Ortiz, 1995a.

FENSTERSEIFER, E. J.; GOMES, A. J. Estratégias de produção na indústria calçadista: análise do best-practice. In: FENSTERSEIFER, J. E. (Org.). O complexo calçadista em perspectiva: tecnologia e competitividade. Porto Alegre: Ortiz, 1995b.

FERNADES, F. C. F. A pesquisa em Gestão da Produção: evolução e tendências. In: ENCONTRO NACIONAL DE ENGENHARIA DE PRODUÇÃO - ENEGEP, 19., 1999, Rio de Janeiro. Anais... Rio de Janeiro: UFRJ; ABEPRO, 1999. 1 CD-ROM. (Trabalho apresentado também no $5^{\circ}$ International Congress of Industrial Engineering).

FERNADES, F. C. F.; MATTIUZZO, M. P. Diagnóstico e avaliação de uma pequena indústria de calçados. Revista Tecnicouro, v. 8, n. 4, p. 50-61, 1986.

FERNANDES, F. C. F.; MURARI, L. S. Diagnóstico dos principais problemas na indústria de calçados femininos. Revista Tecnicouro, v. 20, n. 3 , p. $8-13,2000$ b.

FERNANDES, F. C. F.; MURARI, S. L. Proposta de uma metodologia para cortar peles de couro na indústria de calçados. In: ENCONTRO NACIONAL DE ENGENHARIA DE PRODUÇÃO - ENEGEP, 20., 2000, São Paulo. Anais... São Paulo: USP; ABEPRO, 2000a. 1 CD-ROM

FERRAZ, R. C. Otimização de controle de estoques utilizando a programação dinâmica. 1988. 53 p. Dissertação (Mestrado em Engenharia de Produção) - Universidade Federal de Santa Maria, Santa Maria.

FERREIRA, M. O espaço edificado e a indústria de calçados em Franca. 1989. 89 p. Dissertação (Mestrado) - Universidade de São Paulo, São Carlos.

FILIPPINI, R. Operations management research: some reflections on evolution, models and empirical studies in OM. International Journal of Operations and Production Management, v. 17, n. 7, p. 665-670, 1997.

FRANCISCHINI, N. S. A.; AZEVEDO, F. P. Estratégias das empresas do setor calçadista diante do novo ambiente competitivo: análise de três casos. Gestão \& Produção, v. 10, n. 3, p. 251-265, 2003 b.

FRANCISCHINI, N. S. A.; AZEVEDO, F. P. Impactos do novo ambiente competitivo em empresas do setor calçadista. In: ENCONTRO NACIONAL DE ENGENHARIA DE PRODUÇÃO ENEGEP, 23., 2003, Ouro Preto. Anais... Ouro Preto: UFOP; ABEPRO, 2003a. 1 CD-ROM.

FRANCISCHINI, N. S. A.; AZEVEDO, F. P. Mudanças técnicas e institucional: impactos sobre empresa do setor calçadista. In: ENCONTRO NACIONAL DE ENGENHARIA DE PRODUÇÃO ENEGEP, 22., 2002, Curitiba. Anais... Curitiba: PUC-PR; ABEPRO, 2002. 1 CD-ROM.

FUSCO, A. P. J.; SACOMANO, B. J. Agglomeration and clusters: the leather-shoe sector in the regions of Franca and Jaú/SP. In: ENCONTRO NACIONAL DE ENGENHARIA DE PRODUÇÃO ENEGEP, 21., 2001, Salvador. Anais... Salvador: FTC; ABEPRO, 2001a. 1 CD-ROM.
FUSCO, A. P. J.; SACOMANO, B. J. Economias de aglomeração: a cadeia couro-calçados no cluster de Franca/SP. In: SIMPÓSIO NACIONAL DE ENGENHARIA DE PRODUÇÃO -SIMPEP, 2001, Bauru. Anais... Bauru: Editora da Unesp, 2001b. Disponível em: <www.simpep.feb.unesp.br>. Acesso em: 16 de Julho de 2006.

GARCIA, C. R. Aglomerações setoriais ou distritos industriais: um estudo das indústrias têxtil e de calçados no Brasil. 1996. 151 p. Dissertação (Mestrado em Economia) - Universidade Estadual de Campinas, Campinas.

GARCIA, C. R. Vantagens competitivas de empresas em aglomerações industriais: um estudo aplicado à indústria brasileira de calçados e sua inserção nas cadeias produtivas globais. 2001. 160 p. Tese (Doutorado em Economia) - Instituto de Economia, Universidade Estadual de Campinas, Campinas.

GARCIA, S. A. Análise de estratégias de produção em empresas calçadistas de couro da região do Vale do Rio Sinos. 1997. 158 p. Dissertação (Mestrado em Engenharia de Produção) - Universidade Federal do Rio Grande do Sul, Porto Alegre.

GARVIN, D. A. Gerenciando a qualidade: a visão estratégica e competitiva. Rio de Janeiro: Ed. Qualitymark, 1992.

GAY, L. R.; DIEHL, P. L. Research methods for business and management. New York: Macmillan, 1992.

GIUSTI, R. C. Análise do grau de competitividade das exportações brasileiras de calçados de couro por meio do modelo de campos e armas da competição. 2005. 118 p. Dissertação (Mestrado em Engenharia de Produção) - Universidade Paulista - UNIP, Bauru.

GODINHO FILHO, M. Paradigmas estratégicos de gestão da manufatura: configuração, relações com o planejamento e controle da produção e estudo exploratório na indústria de calçados. 2004. 330 p. Tese (Doutorado em Engenharia de Produção) - Universidade Federal de São Carlos, São Carlos.

GODINHO FILHO, M.; FERNANDES, F. C. F. Um sistema para classificar e codificar os trabalhos relacionados com o Controle da Produção e o Controle da Qualidade. Revista Gestão \& Produção, v. 10, n. 1, p. 35-55, 2003.

GOMES, A. J. Estratégia de produção na indústria calçadista de couro no Vale do Rio dos Sinos. 1993. 249 p. Dissertação (Mestrado em Administração) - Universidade Federal do Rio Grande do Sul, Porto Alegre.

GOOD, I. J. Categorisation of classification. In: Mathematics and computer science in medicine and biology. London: HMSO, 1965. p. 115-128.

GUIMARÃES, M. B. L.; RENNER, S. J. A questão da postura de trabalho no setor de costura da indústria calçadista. In: ENCONTRO NACIONAL DE ENGENHARIA DE PRODUÇÃO - ENEGEP, 23., 2003, Ouro Preto. Anais... Ouro Preto: UFOP; ABEPRO, 2003. 1 CD-ROM.

HANSEN, B. P.; BIASOLI, K. P.; CORTEZIA, S.; RITTER, F. Análise do arranjo coureiro - calçadista do RS a luz do conceito de competitividade sistêmica. In: ENCONTRO NACIONAL DE ENGENHARIA DE PRODUÇÃO - ENEGEP, 24., 2004, Florianópolis. Anais... Florianópolis: UFSC; ABEPRO, 2004. 1 CD-ROM.

HANZL-WEI $\beta$, D. Enlargement and the textiles, clothing and footwear industry. Vienna: The Vienna Institute for International Economic Studies. Documento não-publicado.

HARFIELD, T.; HAMILTON, T. R. Journeys in a declining industry: stories of footwear manufacturing. Journal of Organizational Change Management, v. 10, n. 1, p. 61-70, 1997.

HENRIQUES, S. M. Qualidade, produtividade e gerenciamento de pequenas empresas: um estudo da indústria calçadista de Nova Serrana-MG. 2001. 110 p. Dissertação (Mestrado em Engenharia de Produção) - Departamento de Engenharia de Produção, Universidade Federal de Santa Catarina, Florianópolis. 
HERNANDEZ, F. P. F. Relações entre a gestão da qualidade e a terceirização. 2003. 126 p. Dissertação (Mestrado em Engenharia Mecânica) - Universidade Estadual de Campinas, Campinas.

HOLANDA, L. M. C.; SILVA, R. J. A.; ROSAS, I. A.; CANDIDO, G. A. A relação entre os modelos de gerência e as práticas da gestão do conhecimento: um estudo exploratório na indústria de calçados em Campina Grande-PB. In: SIMPÓSIO NACIONAL DE ENGENHARIA DE PRODUÇÃO - SIMPEP, 12., 2005, Bauru. Anais... Bauru: Editora da Unesp, 2005. Disponível em: <www. simpep.feb.unesp.br>. Acesso em: 16 de Julho de 2006.

HOLLINGUM, J. Quick-change automation for shoe manufacture. Assembly Automation, v. 16, n. 3, p. 34-39, 1996a.

HOLLINGUM, J. Stitching shoes and much more. Assembly Automation, v. 16, n. 3, p. 32-33, 1996b.

HSING, Y. Trading companies in Taiwan's fashion shoe networks. Journal of International Economics, v. 48, p. 101-120, 1999.

KIM, W. T.; KO, S. C.; KIM, N. B. An agent-based framework for global purchasing and manufacturing in a shoe industry. Computers \& Industrial Engineering, v. 42, p. 495-506, 2002.

KINLOCH, V. D. Clusters e redes de cooperação produtiva: alternativas para o desenvolvimento sustentável de PMEs na Nicarágua. 2002. 115 p. Dissertação (Mestrado em Administração de Empresas) - Pontifícia Universidade Católica, Rio de Janeiro.

KMITA, F. S.; GUIMARÃES, M. B. L.; SILVA, M. E. Avaliação das condições físico-ambientais do setor de rebites de uma empresa do setor calçadista. In: ENCONTRO NACIONAL DE ENGENHARIA DE PRODUÇÃO - ENEGEP, 23., 2003, Ouro Preto. Anais... Ouro Preto: UFOP; ABEPRO, 2003. 1 CD-ROM.

KNORRINGAR, P. Economics of collaboration in producer-trader relations: transaction regimes between market and hierarchy in the Agra footwear cluster, Índia. Amsterdam: Vrije Universiteit, 1995.

KOCHAN, A. Actis and the shoe industry. Assembly automation, v. 16, n. 3, p. 30-31, 1996.

KOPPEL, P. S. J. Baker: change is good for the sole. Journal of Systems Management, v. 43, n. 8, p. 12-17, 1992.

LAGES, G. M. A. A relocação espacial da indústria de calçados de couro brasileira na década de 90: aspectos teóricos e empíricos. 2003. 162 p. Tese (Doutorado em Economia) - Instituto de Economia, Universidade Federal do Rio de Janeiro, Rio de Janeiro.

LEITE, B. R. Metodologia para diagnosticar problemas e necessidades da área produtiva e sua aplicação em pequenas e médias fundições e em fabricantes de calçados. 2003. 118 p. Dissertação (Mestrado em Engenharia de Produção) - Universidade Federal de São Carlos, São Carlos.

LEITE, B. R.; FERNANDES, F. C. F. Automação industrial e sistemas informatizados de Gestão da Produção em pequenos e médios fabricantes de calçados. In: SIMPÓSIO NACIONAL DE ENGENHARIA DE PRODUÇÃO - SIMPEP, 10., 2003, Bauru. Anais... Bauru: Editora da Unesp, 2003a. Disponível em: <www. simpep.feb.unesp.br>. Acesso em: 16 de Julho de 2006.

LEITE, R. B.; FERNANDES, F. C. F. Perfil dos pequenos e médios fabricantes de calçados da cidade de Birigui/SP. Revista Tecnicouro, v. 24, n. 8, p. 49-56, 2003 b.

LEMOS, C. Arranjos produtivos locais no Brasil: o caso do arranjocoureiro-calçadista de Campina Grande (PB). Revista Parcerias Estratégicas, v. 15, n. 17, p. 31-53, 2003.

LIMA, A. S. Gestão da qualidade na indústria de calçados de Franca-SP. 2002. 114 p. Dissertação (Mestrado em Engenharia de Produção) - Universidade Federal de São Carlos, São Carlos.

LIMA, A. S.; MARTINS, F. M. A gestão da qualidade na indústria de calçados de Franca-SP. In: SIMPÓSIO DE ADMINISTRAÇÃO DA PRODUÇÃO, LOGÍSTICA E OPERAÇÕES INTERNACIONAIS, 5., 2002, São Paulo. Anais... São Paulo: FGV, 2002. 1 CD-ROM.

LIMA, A. S.; MARTINS, F. M. A indústria de calçados de couro no Brasil: uma descrição a partir do modelo de Porter. In: ENCONTRO
NACIONAL DE ENGENHARIA DE PRODUÇÃO - ENEGEP, 21., 2001, Salvador. Anais... Salvador: FTC; ABEPRO, 2001. 1 CD-ROM.

LINDEN, J. C. S. V. D.; GUIMARÃES, L. B. M. Avaliação da percepção de risco no uso de calçados femininos. In: ENCONTRO NACIONAL DE ENGENHARIA DE PRODUÇÃO - ENEGEP, 25., 2005, Porto Alegre. Anais... Porto Alegre: UFRGS; ABEPRO, 2005. 1 CD-ROM.

LOPES, J. R.; FERNANDES, F. C. F. Uma nova visão sobre a escolha do sistema de custeio para a indústria de calçados. Revista Tecnicouro, v. 25, n. 3, p. 106-113, 2004.

MACHADO, A. G. C.; CARMO, F. D. C. F.; MORAES, W. F. A. Estratégias de customização em massa: evidências e análises no setor calçadista brasileiro. In: SIMPÓSIO NACIONAL DE ENGENHARIA DE PRODUÇÃO - SIMPEP, 12., 2005, Bauru. Anais... Bauru: Editora da Unesp, 2005. Disponível em: <www. simpep.feb.unesp.br>. Acesso em: 16 de Julho de 2006.

MACHADO NETO, A. J. Os derterminantes do comportamento exportador na indústria calçadista francana. 2006. 274 p. Dissertação (Mestrado em Economia) - Faculdade de Economia, Administração e Contabilidade, Universidade de São Paulo, São Paulo.

MARASEA, C. C. D.; CALDANA, F. C. A.; NASSIF, J. M. $\mathrm{V}$. Indicadores de responsabilidade social e perspectivas de qualidade de vida no trabalho em uma indústria calçadista de médio porte. In: SIMPÓSIO NACIONAL DE ENGENHARIA DE PRODUÇÃO - SIMPEP, 11., 2004, Bauru. Anais... Bauru: Editora da Unesp, 2004. Disponível em: <www.simpep.feb.unesp. br>. 16 de Julho de 2006.

MARTINS, S. S. Atividades de logística em uma indústria de calçados: um estudo de caso. In: SIMPÓSIO NACIONAL DE ENGENHARIA DE PRODUÇÃO - SIMPEP, 12., 2000, Bauru. Anais... Bauru: Editora da Unesp, 2000. Disponível em: <www. simpep.feb.unesp.br>. Acesso em: 16 de Julho de 2006.

MAZOCATO, A. M. Canais de distribuição na exportação: descrição da estrutura de distribuição das exportações de calçados produzidos no Vale do Rio dos Sinos no Rio Grande do Sul. 1989b. 159 p. Dissertação (Mestrado em Administração) - Universidade Federal do Rio Grande do Sul, Porto Alegre.

MAZOCATO, A. M. Canais de exportação do calçado brasileiro. Revista de Administração de Empresas, v. 29, n. 4, p. 71-81, 1989a.

MOLLO NETO, M.; VENDRAMETTO, O. Proposta de um sistema automatizado de inspeção para apoio ao controle da qualidade em indústrias de curtume. In: SIMPÓSIO DE ADMINISTRAÇÃO DA PRODUÇÃO, LOGÍSTICA E OPERAÇÕES INTERNACIONAIS, 6., 2003, São Paulo. Anais... São Paulo: FGV, 2003. 1 CD-ROM.

MOREIRA, M. E. O nível de inovação tecnológica da indústria de calçados de couro no Vale dos Sinos: determinantes e tendências a inovar. 1987. 162 p. Dissertação (Mestrado em Economia) Universidade Federal do Rio Grande do Sul, Porto Alegre.

MORES, J. C. A alocação de custos indiretos na indústria de calçados na região do Vale dos Sinos (RS). 1988. 348 p. Dissertação (Mestrado em Ciências Contábeis) - Fundação Getúlio Vargas, Rio de Janeiro.

MOTTA, G. F. Cluster regional calçadista de Franca e a cooperação entre as empresas: estudo de casos. In: SIMPÓSIO NACIONAL DE ENGENHARIA DE PRODUÇÃO - SIMPEP, 8., 2001, Bauru. Anais... Bauru: UNESP, 2001. Disponível em: <www.simpep. feb.unesp.br>. Acesso em: 16 de Julho de 2006.

MOTTA, G. F.; ESCRIVÃO FILHO, E. Cluster como estratégia competitiva para pequenas empresas: o setor calçadista de Franca-SP pode beneficiar-se desta nova forma associativa? In: SIMPÓSIO NACIONAL DE ENGENHARIA DE PRODUÇÃO SIMPEP, 10., 2003, Bauru. Anais... Bauru: UNESP, 2003. Disponível em: <www.simpep.feb.unesp.br>. Acesso em: 16 de Julho de 2006. 
MURARI, S. L. Contribuição ao estudo dos problemas de controle da produção e corte de materiais na indústria de calçados. 1997. 130 p. Dissertação (Mestrado em Engenharia de Produção) - Universidade Federal de São Carlos, São Carlos.

NADALETO, A. T. Estratégias de produção e prioridades competitivas: estudo de caso em empresas do pólo calçadista de Jaú. 2003. 162 p. Dissertação (Mestrado em Engenharia de Produção) - Escola de Engenharia de São Carlos, Universidade de São Paulo, São Carlos.

NARAIN, R.; YADAV, C. R.; ANTONY, J. Productivity gains from flexible manufacturing, experiences from India. International Journal of Productivity and Performance Management, v. 53, n. 2, p. 109-128, 2004

NAVARRO, L. V. A produção de calçados de couro em Franca (SP): a reestruturação produtiva e seus impactos sobre o trabalho. 1998. 301 p. Tese (Doutorado em Sociologia) - Universidade Estadual Paulista Júlio de Mesquita, Araraquara.

NAVARRO, L. V. O trabalho e a saúde do trabalhador na indústria de calçados. São Paulo em Perspectiva, v. 17, n. 2, p. 32-41, 2003

NEUMAN, W. L. Social research methods. 5 ed. Boston: Allyn and Bacon, 2003.

NISANCI, I. H.; SURY, J. R. An application of group technology concepts in shoe manufacturing. International Journal of Production Research, v. 19, n. 3, p. 267-275, 1981

NISANCI, I. H.; SURY, J. R. Production analysis by simulation in a shoe manufacturing factory. International Journal of Production Research, v. 18, n. 1, p. 31-41, 1980.

ORSSATTO, H. C. A formulação das estratégias da empresa em um ambiente de aglomeração industrial. 2002. 220 p. Tese (Doutorado em Engenharia de Produção) - Universidade Federal de Santa Catarina, Florianópolis.

ORSSATTO, J. R. A influência dos modos de racionalidade na estruturação das indústrias calçadistas de Novo Hamburgo. In: FENSTERSEIFER, J. E. (Org.). O complexo calçadista em perspectiva: tecnologia e competitividade. Porto Alegre: Ortiz, 1995

ORSSATTO, J. R. Imperativos organizacionais e modos de racionalidade: um estudo sobre a estruturação das organizações industriais calçadistas do município de Novo Hamburgo-RS. 1994. 202 p. Dissertação (Mestrado em Administração de Empresas) - Centro Sócio-Econômico, Universidade Federal de Santa Catarina, Florianópolis.

PACE, U. S. E.; CORREDATO, S.; FALGETANO, P. T. O impacto da desvalorização do real no índice de desemprego do setor calçadista argentino: um estudo sobre a vulnerabilidade econômica nos blocos comerciais. In: SIMPÓSIO DE ADMINISTRAÇÃO DA PRODUÇÃO, LOGÍSTICA E OPERAÇÕES INTERNACIONAIS, 6., 2003, São Paulo. Anais... São Paulo: FGV, 2002. 1 CD-ROM

PEGATIN, O. T.; SILVA, M. F. Análise ergonômica de um posto de trabalho numa fábrica de calçados. In: SIMPÓSIO NACIONAL DE ENGENHARIA DE PRODUÇÃO - SIMPEP, 11., 2004, Bauru. Anais... Bauru: UNESP, 2004. Disponível em: <www. simpep.feb.unesp.br>. Acesso em: 16 de Julho de 2006.

PEREIRA, D. M. J. Flexibilidade da produção e subcontratação do trabalho: o caso da indústria gaúcha de calçados de couro. 1998. 264 p. Tese (Doutorado em Economia) - Universidade Federal de Pernambuco, Santa Maria.

PEREIRA, M. G. Avaliação do impacto das mudanças mercadológicas sobre o perfil de competências gerenciais nas empresas calçadistas gaúchas voltadas à exportação. 2001. 221 p. Tese (Doutorado em Engenharia de Produção) - Escola Politécnica, Universidade de São Paulo, São Paulo.

PEREIRA, M. G.; BRUNSTEIN, I. Avaliação do impacto das mudanças mercadológicas sobre o perfil de competências gerenciais nas empresas calçadistas gaúchas voltadas à exportação. São Paulo: EPUSP, 2002b. 30 p. Boletim Técnico da Escola Politécnica da USP.

PEREIRA, M. G.; BRUNSTEIN, I. Managerial competencies as a restriction to a faster product and process development in the shoe industry. In: ENCONTRO NACIONAL DE ENGENHARIA DE PRODUÇÃO - ENEGEP, 23., 2003, Ouro Preto. Anais... Ouro Preto: UFOP/ ABEPRO, 2003. 1 CD-ROM.

PEREIRA, M. G.; BRUNSTEIN, I. Up grade do cluster calçadista gaúcho voltado à exportação: a barreira das competências gerenciais. In: ENCONTRO NACIONAL DE ENGENHARIA DE PRODUÇÃO - ENEGEP, 22., 2002, Curitiba. Anais... Curitiba: PUC-PR/ABEPRO, 2002a. 1 CD-ROM.

PEREZ-ALEMAN, P. Learning, adjustment and economic development: transforming firms, the state and associations in Chile. World Development, v. 28, n. 1, p. 41-55, 2000.

PERRY, M.; SOHAL, S. A.; RUMPF, P. Quick response supply chain alliances in the Australian textiles, clothing and footwear industry. International Journal of Production Economics, v. 62, n. 5, p. 119-132, 1999.

PERRY, M.; SOHAL, S. A. Effective quick response pactices in a suplly chain partnership. International Journal of Operations \& Production Management, v. 21, n. 5/6, p. 840-854, 2001.

PICCININI, C. V. Mudanças na indústria calçadista brasileira: novas tecnologias e globalização do mercado. Read - Revista Eletrônica de Administração, v. 1, n. 1, p. 45-58, 1995a. Disponível em: <www.read.ea.ufrgs.br>. Acesso em: 20 de Julho de 2006.

PICCININI, C. V. Mudanças na indústria calçadista brasileira: novas tecnologias e globalização do mercado. In: FENSTERSEIFER, J. E. (Org.). O complexo calçadista em perspectiva: tecnologia e competitividade. Porto Alegre: Ortiz, 1995b.

PICCININI, C. V. Novas formas de organização do trabalho na indústria calçadista. Revista de Administração, v. 27, n. 2, p. 33-40, 1992.

PICCININI, C. V. Tecnologia e qualificação profissional na indústria calçadista do Vale dos Sinos. Revista de Administração, v. 29, n. 1, p. 59-66, 1994.

PINNOTTI, E. S. Proposta de implantação de um modelo de desenvolvimento de produtos no setor de modelagem de uma empresa de calçados. 2003. 142 p. Dissertação (Mestrado em Engenharia de Produção) - Escola de Engenharia, Universidade Federal do Rio Grande do Sul, Porto Alegre.

PINTO, D. C.; SCHRAMM, F. Otimização do planejamento da produção de uma indústria de calçados. In: ENCONTRO NACIONAL DE ENGENHARIA DE PRODUÇÃO - ENEGEP, 25., 2005, Porto Alegre. Anais... Porto Alegre: UFRGS/ABEPRO, 2005. 1 CD-ROM.

RABELLOTTI, R. Collective effects in italian and mexican footwear industrial clusters. Small Business Economics, v. 10, n. 2, p. 243-262, 1998

RABELLOTTI, R. Industrial districts in México: the case of the footwear industry. Small Enterprise Development, v. 4, n. 3, p. 26-36, 1993.

RABELLOTTI, R. Is there an "industrial district model"? Footwear districts in Italy and México compared. World Development, v. 23, n. 1, p. 29-41, 1995 .

REHFELDT, H. J. M. Uma heurística aplicada a um problema de escalonamento na indústria calçadista. 2001. 122 p. Dissertação (Mestrado em Administração de Empresas) - Escola de Administração, Universidade Federal do Rio Grande do Sul, Porto Alegre.

REIS, M. Reestruturação internacional e inserção do Brasil na indústria de calçados. 1992. 140 p. Dissertação (Mestrado em Economia) - Universidade Estadual de Campinas, Campinas.

REIS, N. C. A indústria brasileira de calçados: inserção internacional e dinâmica interna nos anos 80. 1994. 257 p. Tese (Doutorado em Economia) - Universidade Estadual de Campinas, Campinas.

RENNER, S. J. Custos posturais nos posicionamentos em pé, em pé/sentado e sentado nos postos de trabalho de costura na 
indústria calçadista. 2002. 102 p. Dissertação (Mestrado em Engenharia de Produção) - Escola de Engenharia, Universidade Federal do Rio Grande do Sul, Porto Alegre.

RENTES, F. A.; SILVA, L. A.; SILVA, O. C. V.; CASTRO, A. S. Aplicando os conceitos de lean production em uma indústria de calçados: um estudo de caso. In: SIMPÓSIO NACIONAL DE ENGENHARIA DE PRODUÇÃO - SIMPEP, 10., 2003, Bauru. Anais... Bauru: UNESP, 2003. Disponível em: <www.simpep. feb.unesp.br>. Acesso em: 16 de Julho de 2006.

REVISTA COUROBUSINESS. Novo Hamburgo: Courobusiness, 2008. Disponível em: <http://www.courobusiness.com.br>. Acesso em: 13 de Novembro de 2008.

RHODEN, S. I. M. Administração estratégica aplicada a uma associação de indústrias. Read -Revista Eletrônica de Administração, v. 9, n. 2, 2003. Disponível em: <www.read. ea.ufrgs.br>. Acesso em: 20 de Julho de 2006.

RIBEIRO, A. R. Reestruturação da indústria calçadista e seus impactos sobre o trabalho: estudo de casos a partir do pólo gaúcho. 2000. 203 p. Tese (Doutorado em Economia) - Instituto de Economia, Universidade Federal do Rio de Janeiro, Rio de Janeiro.

ROCHA, R. E. V.; ELIAS, S. J. B. Transferência de tecnologia no setor de plásticos e calçados da Região Nordeste. O caso do projeto unidades móveis. In: SIMPÓSIO NACIONAL DE ENGENHARIA DE PRODUÇÃO - SIMPEP, 12., 2005, Bauru. Anais... Bauru: UNESP, 2005. Disponível em: <www.simpep. feb.unesp.br>. Acesso em: 16 de Julho de 2006.

ROCHA, S. A. Estratégias de sobrevivência das microempresas do setor de calçados do estado do Ceará: reflexão a partir dos principais pólos de produção. 1990. 265 p. Dissertação (Mestrado em Economia) - Universidade Federal do Ceará, Fortaleza.

ROESCH, A. M. S. Flexibilidade no trabalho e estratégias de recursos humanos. In: FENSTERSEIFER, J. E. (Org.). O complexo calçadista em perspectiva: tecnologia e competitividade. Porto Alegre: Ortiz, 1995.

ROOKS, W. B. Robots bring automation to shoe production. Assembly Automation, v. 16, n. 3, p. 22-25, 1996.

RUAS, L. R. Processo de trabalho e controle do capital: caso da indústria de calçados no Rio Grande do Sul. 1987. 396 p. Tese (Doutorado em Sociologia) - Universidade Federal do Rio Grande do Sul, Porto Alegre.

RUAS, R. O conceito de cluster e as relações interfirmas no complexo calçadista do Rio Grande do Sul. In: FENSTERSEIFER, J. E. (Org.). O complexo calçadista em perspectiva: tecnologia e competitividade. Porto Alegre: Ortiz, 1995.

RUPPENTHAL, E. J. Perspectivas do setor couro do estado do Rio Grande do Sul. 2001. 244 p. Tese (Doutorado em Administração de Empresas) - Universidade Federal de Santa Catarina, Florianópolis.

SALOMÃO, S. Estratégia de produção e gestão de pessoal: estudos de caso em empresas da indústria de calçados de couro do pólo de Franca-SP. 1998. 172 p. Dissertação (Mestrado em Engenharia de Produção) - Departamento de Engenharia de Produção, Universidade Federal de São Carlos, São Carlos.

SALOMÃ̃O, S.; ALVES FILHO, G. A. Estratégia de produção e gestão de pessoal: estudo de caso na indústria calçadista de Franca-SP. In: ENCONTRO NACIONAL DE ENGENHARIA DE PRODUÇÃO - ENEGEP, 18., 1998, Niterói. Anais... Niterói: UFF/ABEPRO, 1998. 1 CD-ROM.

SALOMON, D. V. Como fazer uma monografia. São Paulo: Ed. Martins Fontes, 1991.

SANTOS, R. E. M.; CUNHA, V. C. N.; GRAZIADIO, T.; SCHMITT, L. A capacidade tecnológica de uma facção de calçados: o caso da Solasul. In: ENCONTRO NACIONAL DE ENGENHARIA DE PRODUÇÃO - ENEGEP, 17., 1997, Gramado. Anais... Gramado: UFRGS/ABEPRO, 1997. 1 CD-ROM.

SANTOS, S. J. R.; ARAÚJO FILHO, G. J.; NOGUEIRA, C.; SILVA, L. A. P. Impactos do planejamento das instalações e engenharia de métodos na produtividade em uma indústria de calçados do Triângulo CRAJUBAR. In: ENCONTRO NACIONAL DE ENGENHARIA DE PRODUÇÃO - ENEGEP, 23., 2003, Ouro Preto. Anais... Ouro Preto: UFOP/ABEPRO, 2003. 1 CD-ROM.

SANTOS, V. N.A. F. Design: um diferencial de qualidade. Desenvolvendo o processo de design de produtos sob o enfoque da qualidade. 1998. 175 p. Dissertação (Mestrado em Engenharia de Produção) - Universidade Federal do Rio de Janeiro, Rio de Janeiro.

SCARSO, E.; BOLISANI, E. Tecnology transfer to supplier-dominated sectors. Lessons form the diffusion of CAD in the fashion industry. International Journal of Technology Management, v. 12, n. 4, p. 421-437, 1996.

SCHMITZ, H. Global competition and local cooperation: sucess and failure in the Sinos Valley, Brazil. World Development, v. 27, n. 9, p. 1627-1650, 1999.

SCHMITZ, H. Small shoemakers and fordist giants: tale of a supercluster. World Development, v. 23, n. 1, p. 9-28, 1995.

SCOTT, A. J. The changing global geography of low-technology, labor-intensive industry: clothing, footwear and furniture. World Development, v. 34, n. 9, p. 1517-1536, 2006.

SELLITTO, M. A. Considerações sobre a mentalidade enxuta: um modelo para aplicação imediata em empresas do setor coureirocalçadista. Revista Tecnicouro, v. 22, n. 6, p. 85-96, 2001 b.

SELLITTO, M. A. O que é Teoria das Restrições e como pode ser aplicada na indústria calçadista. Revista Tecnicouro, v. 22, n. 2, p. 10, 2001a.

SELLITTO, M. A. Sistema Toyota de Produção: é possível aplicá-lo na indústria calçadista? Revista Tecnicouro, v. 21, n. 7, p. 23-27, 2000.

SEVEGNANI, X. F.; SACOMANO, B. J. A estratégia de manufatura no setor coureiro calçadista: máquinas operatrizes e equipamentos. In: SIMPÓSIO NACIONAL DE ENGENHARIA DE PRODUÇÃO SIMPEP, 10., 2003b, Bauru. Anais... Bauru: UNESP, 2003b. Disponível em: <www.simpep.feb.unesp.br>. Acesso em: 16 de Julho de 2006.

SEVEGNANI, X. F.; SACOMANO, B. J. As máquinas operatrizes no processo produtivo como estratégia de manufatura na indústria coureiro calçadista. In: ENCONTRO NACIONAL DE ENGENHARIA DE PRODUÇÃO - ENEGEP, 23., 2003, Ouro Preto. Anais... Ouro Preto: UFOP/ABEPRO, 2003 a. 1 CD-ROM.

SEVERO, F. R. M.; MÉLO, N. A. M.; MEDEIROS, D. D. Importância estratégica do sistema de qualidade para aumentar a competitividade empresarial: aplicação em uma empresa de calçados esportivos. In: ENCONTRO NACIONAL DE ENGENHARIA DE PRODUÇÃO ENEGEP, 24., 2004, Florianópolis. Anais... Florianópolis: UFSC/ ABEPRO, 2004. 1 CD-ROM.

SILVA, A. O. A configuração do sistema de produção da indústria de máquinas para couro e calçados e a capacitação tecnológica da cadeia calçadista nacional no período recente. In: ENCONTRO NACIONAL DE ENGENHARIA DE PRODUÇÃO - ENEGEP, 25. 2005, Porto Alegre. Anais... Porto Alegre: UFRGS/ABEPRO, 2005. 1 CD-ROM.

SILVA, C. A.; RIBEIRO, S. M.; GONÇALVES, G. M. C. R. Contabilidade de custos aplicada às indústrias couro-calçadistas da cidade de Franca (Brasil): um estudo de caso. Disponível em: <www.fipecafi.com.br/public_artigos/maisa/couroFranca. pdf $>$. Acesso em: 17 de Outubro de 2004

SILVA, C. G. H. Modelo de desempenho na logística de suprimentos do setor calçadista do Vale do Rio Tijucas de Santa Catarina. 2002c. 142 p. Dissertação (Mestrado em Engenharia de Produção) Departamento de Engenharia de Produção, Universidade Federal de Santa Catarina, Florianópolis.

SILVA, E. S. Análise da aquisição, implantação e uso de sistemas ERP em médias empresas industriais do ramo de calçados. 2002a. 108 p. Dissertação (Mestrado em Engenharia de Produção) - 
Departamento de Engenharia de Produção, Universidade Federal de São Carlos, São Carlos.

SILVA, E. S.; FERNANDES, F. C. F. Proposta da estrutura do sistema ERP e a sua aplicação em estudos de caso. In: SIMPÓSIO DE ADMINISTRAÇÃO DA PRODUÇÃO, LOGÍSTICA E OPERAÇÕES INTERNACIONAIS, 5., 2002, São Paulo. Anais... São Paulo: FGV, 2002a. 1 CD-ROM.

SILVA, F. L. G. Gestão da informação no setor calçadista de Campina Grande. 1999. 108 p. Dissertação (Mestrado em Engenharia de Produção) - Universidade Federal da Paraíba, João Pessoa.

SILVA, F. M.; FERNANDES, F. C. F. Uma proposta de seqüenciamento de operações para a produção de calçados em um ambiente de fluxo controlado. Revista Tecnicouro, v. 23, n. 9, p. 71-78, 2002b.

SILVA, J. F. A utilização da inteligência artificial aplicada à ergonomia, no estudo de caso: indústrias de calçados na cidade de Birigui-SP. In: SIMPÓSIO NACIONAL DE ENGENHARIA DE PRODUÇÃO - SIMPEP, 8., 2001, Bauru. Anais... Bauru: UNESP, 2001. Disponível em: <www.simpep.feb.unesp.br>. Acesso em: 16 de Julho de 2006.

SILVA, M. F. Um sistema de planejamento e controle da produção para fabricantes de calçados infantis pertencentes a um industrial cluster. 2002b. Dissertação (Mestrado em Engenharia de Produção) - Departamento de Engenharia de Produção, Universidade Federal de São Carlos, São Carlos.

SILVA, M. L. C.; FONSECA, S. V. Configuração estrutural da indústria calçadista de Novo Hamburgo. In: FENSTERSEIFER, J. E. (Org.). O complexo calçadista em perspectiva: tecnologia e competitividade. Porto Alegre: Ortiz, 1995.

SILVA, S. E.; FERNANDES, F. C. F. Análise da influência do comportamento de fabricantes de calçados de médio porte sobre os resultados da implantação de sistemas ERP. In: SIMPÓSIO DE ADMINISTRAÇÃO DA PRODUÇÃO, LOGÍSTICA E OPERAÇÕES INTERNACIONAIS, 6., 2003, São Paulo. Anais... Local de publicação, 2003. 1 CD-ROM.

SILVA, S. E.; FERNANDES, F. C. F. Aspectos do uso de sistemas ERP e sua aplicação na indústria calçadista. Revista Tecnicouro, v. 25, n. 6, p. 34-38, 2004.

SOUSA, A. K. F.; BARBOSA, A. E.; BARRETO, G. L. M. O modelo de "Gestão da Produção enxuta", como instrumento de competitividade numa indústria de calçados. In: SIMPÓSIO NACIONAL DE ENGENHARIA DE PRODUÇÃO - SIMPEP, 11., 2004, Bauru. Anais... Bauru: UNESP, 2004. Disponível em: <www.simpep.feb.unesp.br>. Acesso em: 16 de Julho de 2006.

SOUSA, T. R. V.; ALVES, J. S.; MOUTINHO, L. M. G.; CAVALCANTI FILHO, P. F. M. B. Um estudo de arranjos produtivos e inovativos locais de calçados no Brasil: os casos do Rio Grande do Sul, São Paulo e Paraíba. Revista Teoria e Evidência Econômica, v. 13, n. 24, p. 61-78, 2005.

SOUZA, A. A. Relações de trabalho: um estudo sobre as operárias do setor de calçados. 1993. 182 p. Dissertação (Mestrado em Administração) - Universidade Federal de Minas Gerais, Belo Horizonte.

SOUZA, B. G. Um sistema de planejamento e controle da produção para uma associação que coordena empresas exportadoras pertencentes a um industrial cluster de calçados. 2002. 136 p. Dissertação (Mestrado em Engenharia de Produção) - Universidade Federal de São Carlos, São Carlos.

SOUZA, G. B.; FERNANDES, F. C. F. Aglomerado industrial no ramo de calçados: conceituação e estudo de caso. Revista Tecnicouro, v. 22, n. 8, p. 97-106, 2001.

SPENCER Jr., E. J. Robotics technology and the advent of agile manufacturing systems in the footwear industry. Assembly automation, v. 16, n. 3, p. 10-15, 1996.

SUZIGAN, W.; GARCIA, R.; FURTADO, J. Governança de sistemas de MPMEs em clusters industriais. In: SEMINÁRIO INTERNACIONAL "POLÍTICAS PARA SISTEMAS
PRODUTIVOS LOCAIS DE MPMES”, 2002, Rio de Janeiro. Anais... Rio de Janeiro, 2002.

TOMELIN, B. L. A formação de consórcios de exportação em Santa Catarina. 2000. 108 p. Dissertação (Mestrado em Tecnologia de Produção) - Centro Tecnológico, Universidade Federal de Santa Catarina, Florianópolis.

TRISTÃO, M. H. Cluster como elo de integração entre as indústrias. In: SIMPÓSIO DE ADMINISTRAÇÃO DA PRODUÇÃO, LOGÍSTICA E OPERAÇÕES INTERNACIONAIS, 5., 2002, São Paulo. Anais... São Paulo : FGV, 2002. 1 CD-ROM.

TUBINO, F. D.; LOPES, C. M. Reestruturação do sistema de produção de uma empresa calçadista: um estudo de caso. In: ENCONTRO NACIONAL DE ENGENHARIA DE PRODUÇÃO - ENEGEP, 16., 1996, Piracicaba. Anais... Piracicaba: UNIMEP/ABEPRO, 1996. 1 CD-ROM.

VARGAS, M.; ALIEVI, R. Trajetórias de aprendizado e estratégias de capacitação no arranjo produtivo coureiro-calçadista do Vale dos Sinos (RS). Revista Parcerias Estratégicas, n. 17, p. 135-164, 2003.

VASCONCELOS, P. R. C.; FERREIRA, S. A. A. Dificuldades de implementação de políticas de responsabilidade social e ecológica em comunidades locais: o caso da Courotex. In: ENCONTRO NACIONAL DE ENGENHARIA DE PRODUÇÃO - ENEGEP, 24., 2004, Florianópolis. Anais... Florianópolis: UFSC/ABEPRO, 2004. 1 CD-ROM.

VECCHIO, A. R. Autonomia para a competitividade: o futuro da indústria coureiro-calçadista do Rio Grande do Sul. Read Revista Eletrônica de Administração, v. 6, n. 4, p. 65-78, 2000. Disponível em: <www.read.ea.ufrgs.br>. Acesso em: 16 de Julho de 2006.

VENDRAMETO, O.; GIANNETTI, F. B.; BRUNSTEIN, I. Avaliação dos pontos críticos da cadeia produtiva carne, couro e calçados. In: ENCONTRO NACIONAL DE ENGENHARIA DE PRODUÇÃO ENEGEP, 21., 2001, Salvador. Anais... Salvador: FTC/ABEPRO, 2001. 1 CD-ROM.

VERGARA, S. C. Projetos e relatórios de pesquisa em administração. 5 ed. São Paulo: Atlas, 2004.

VIEGAS, C. Relações entre capacidade tecnológica e gestão de resíduos sólidos industriais: estudo de casos em empresas calçadistas do Vale dos Sinos. 1997. 149 p. Dissertação (Mestrado em Administração) - Universidade Federal do Rio Grande do Sul, Porto Alegre.

WOODRUFF, C. Contract enforcement and trade liberalization in Mexico's footwear industry. World Development, v. 26, n. 6, p. 979-991, 1998

WOODRUFF, C. Non-contractible investments and vertical integration in the mexican footwear industry. International Journal of Industrial Organization, v. 20, n. 1, p. 1197-1224, 2002.

WU, H. T.; CHEN, F. J.; LOW, C.; TANG, T. P. Nesting of two-dimensional parts in multiple plates using hybrid algorithm. International Journal of Production Research, v. 41, n. 16, p. 3883-3900, 2003.

YIN, R. K. Case study research: design and methods. 2 ed. London: Sage Publications, 1994.

ZANGIACOMI, A.; ZHIJIAN, L.; SACCO, M.; BOËR, C. R. Process planning and scheduling for mass customised shoe manufacturing. International Journal of Computer Integrated Manufacturing, v. 17, n. 7, p. 613-621, 2004.

ZANINI, K. R. M.; OLIVEIRA, P. C. L. Adaptação estratégica organizacional em uma empresa do setor calçadista do Vale dos Sinos-RS. In: ENCONTRO NACIONAL DE ENGENHARIA DE PRODUÇÃO - ENEGEP, 24., 2004, Florianópolis. Anais... Florianópolis: UFSC/ABEPRO, 2004. 1 CD-ROM.

ZAWISLAK, A. P. A inovação no setor calçadista brasileiro: um exemplo de atividade de resolução de problemas. In: FENSTERSEIFER, J. E. (Org.). O complexo calçadista em perspectiva: tecnologia e competitividade. Porto Alegre: Ortiz, 1995. 


\section{Sobre os autores}

\section{Moacir Godinho Filho}

Departamento de Engenharia de Produção

Universidade Federal de São Carlos - UFSCar

Rod. Washington Luís, Km 235, CEP 13565-905, São Carlos - SP

e-mail: moacir@dep.ufscar.br

\section{Flávio César Faria Fernandes}

Departamento de Engenharia de Produção

Universidade Federal de São Carlos - UFSCar

Rod. Washington Luís, Km 235, CEP 13565-905, São Carlos - SP

e-mail: dfcf@ power.ufscar.br

\section{Andrey Domingues de Lima}

Departamento de Engenharia de Produção

Universidade Federal de São Carlos - UFSCar

Rod. Washington Luís, Km 235, CEP 13565-905, São Carlos - SP

e-mail: andreydomingues@yahoo.com.br 